\title{
OPEN Voltage and pH difference across the membrane control the $\$ 4$ voltage-sensor motion of the Hv1 proton channel
}

\author{
T. Moritz Schladt ${ }^{1} \&$ Thomas K. Berger $^{1,2} \bowtie$ \\ The voltage-gated proton channel Hv1 is expressed in a variety of cells, including macrophages, \\ sperm, and lung epithelial cells. Hv1 is gated by both the membrane potential and the difference \\ between the intra- and extracellular $\mathrm{pH}(\Delta \mathrm{pH})$. The coupling of voltage- and $\Delta \mathrm{pH}$-sensing is such \\ that $\mathrm{Hv} 1$ opens only when the electrochemical proton gradient is outwardly directed. However, the \\ molecular mechanism of this coupling is not known. Here, we investigate the coupling between \\ voltage- and $\Delta \mathrm{pH}$-sensing of Ciona intestinalis proton channel (ciHv1) using patch-clamp fluorometry \\ (PCF) and proton uncaging. We show that changes in $\triangle \mathrm{pH}$ can induce conformational changes of the \\ S4 voltage sensor. Our results are consistent with the idea that $\$ 4$ can detect both voltage and $\Delta \mathrm{pH}$.
}

The voltage-gated proton channel Hv1 (the product of the HVCN1 gene; also called voltage-sensor domain-only protein, VSOP) is expressed in a variety of organisms, ranging from single-cell organisms to mammals ${ }^{1-3}$. In humans, Hv1 is expressed in several different immune cells $\mathrm{s}^{4,5}$, lung epithelial cells ${ }^{6}$, and sperm ${ }^{7}$. The physiological role of Hv1 is best understood in macrophages, where the channel regulates the innate immune response to pathogens. Hv1 sustains the production of reactive oxygen species by NADPH oxidase (NOX) activity ${ }^{4,8,9}$, which depolarizes the membrane and acidifies the cytosol. Hv1 activation repolarizes the membrane and counteracts acidification by proton extrusion. In addition, Hv1 has been suggested to regulate B-cell proliferation ${ }^{5}$, sperm maturation $^{7}$, and the $\mathrm{pH}$ at the airway epithelium ${ }^{6}$. Excessive Hvl activity can have pathological consequences. In a mouse model of ischemic stroke, Hv1 activity worsens brain damage ${ }^{10}$. Hv1 is overexpressed in breast-cancer cells ${ }^{11}$ and malignant B-lymphocytes ${ }^{12}$.

Hv1 is a special member of the family of voltage-gated ion channels. Classical voltage-gated ion channels comprise a voltage-sensor domain (VSD), consisting of four transmembrane segments, S1-S4, and a pore domain (PD), consisting of two transmembrane segments (S5 and S6). Four subunits assemble such that the four PDs form a central pore. In contrast, Hv1 consists only of a VSD, lacking the pore domain ${ }^{1,2}$. Reconstituted Hv1 is functional in liposomes ${ }^{13}$, showing that the VSD harbors the pore for proton permeation. The intracellular $\mathrm{C}$-terminal end of $\mathrm{Hv} 1$ contains a coiled-coil domain that promotes dimer formation ${ }^{14-17}$. Each subunit contains its own ion permeation pathway ${ }^{14-16}$, and the subunits are gated cooperatively ${ }^{18,19}$. Amino-acid residues that affect proton selectivity have been identified ${ }^{20,21}$, providing an initial, albeit incomplete picture of the protonpermeation pathway. The gating process involves an outward motion of the main voltage-sensing segment $\mathrm{S} 4^{18}$. An additional conformational change has been identified, which involves the S1 segment and which is concomitant with channel opening ${ }^{22}$.

$\mathrm{Hv} 1$ is not only gated by membrane potential, but also by the $\mathrm{pH}$ difference across the membrane $\left(\Delta \mathrm{pH}=\mathrm{pH}_{\mathrm{o}}-\mathrm{pH}_{\mathrm{i}}\right)$. At $\Delta \mathrm{pH}=0, \mathrm{Hv} 1$ starts to open at +10 to $+30 \mathrm{mV}^{23}$. The activation curve is shifted by approximately $40 \mathrm{mV} / \Delta \mathrm{pH}$ unit to more negative and positive membrane potentials for $\Delta \mathrm{pH}>0$ and $<0$, respectively ("40 $\mathrm{mV}$ rule") 24 . By contrast, changes in $\mathrm{pH}_{\mathrm{o}}$ or $\mathrm{pH}_{\mathrm{i}}$ that leave $\Delta \mathrm{pH}$ constant do not alter the voltage dependence of activation. An important functional consequence of $\Delta \mathrm{pH}$ sensing in Hv1 is outward rectification: the channel only opens when the electrochemical gradient is directed towards the extracellular side (see ${ }^{25}$ for an exception). The amino-acid residues that convey $\Delta \mathrm{pH}$ sensing remain elusive. Although mutants with enhanced or diminished $\Delta \mathrm{pH}$ sensing have been identified ${ }^{26-28}$, no mutants are known that lack $\Delta \mathrm{pH}$ sensing entirely. In summary, coupling between voltage- and $\Delta \mathrm{pH}$-sensing in $\mathrm{Hvl}$ is not well understood.

\footnotetext{
${ }^{1}$ Department of Molecular Sensory Systems, Center of Advanced European Studies and Research (Caesar), Bonn, Germany. ${ }^{2}$ Department of Neurophysiology, Institute of Physiology and Pathophysiology, Philipps-University Marburg, Marburg, Germany. ${ }^{\square}$ email: thomas.berger@uni-marburg.de
} 
Here, we study the mechanism of $\Delta \mathrm{pH}$ sensing in Hv1. Using electrophysiological and fluorescence-optical techniques, we show that the $\mathrm{S} 4$ voltage sensor of ciHv1 changes its conformation in response to changes in $\Delta \mathrm{pH}$. Our results suggest that $\mathrm{S} 4$ is not only the main voltage sensor, but that $\mathrm{S} 4$ also serves as a $\Delta \mathrm{pH}$ sensor.

\section{Methods}

Ethical approval. Xenopus laevis frog oocytes were provided by Christopher Volk (Bonn-Rhein-Sieg University of Applied Sciences, Sankt Augustin, Germany), purchased from Ecocyte (Castrop-Rauxel, Germany), or harvested from our own colony. Frogs were housed according to the German law of animal protection and the district veterinary office. Oocytes were harvested from frogs anesthetized in phosphate-buffered water containing $0.16 \% 3$-aminobenzoate methanesulfonate salt. The surgery followed standard procedures and were carried out in accordance with relevant guidelines and regulations with the approval (84-02.04.2016.A077) of the local authority of the state North Rhine-Westphalia (LANUV) or the approval (Nr. A 16/2019) of the local authority of the state Hesse (Regierungspräsidium Gießen).

DNA constructs and expression in Xenopus oocytes. DNA constructs were cloned and sequenced using standard techniques. The psD64TF vector ${ }^{2}$ containing ciHv1 (accession number NP_001071937) was linearized with SacI, and the region coding for ciHv1 was transcribed using the SP6 mMessage mMachine kit (Ambion, Austin, TX, USA). Xenopus oocytes were injected with $50 \mathrm{nl}$ RNA $(0.1-2 \mu \mathrm{g} / \mu \mathrm{l})$ and incubated at $14-16^{\circ} \mathrm{C}$ for $1-5$ days in ND96 medium containing (in mM): $96 \mathrm{NaCl}, 2 \mathrm{KCl}, 1.8 \mathrm{CaCl}_{2}, 1 \mathrm{MgCl}, 10$ 4-(2-hydroxyethyl)piperazine-1-ethanesulfonic acid (HEPES), $5 \mathrm{Na}$-pyruvate, and $100 \mathrm{mg} / \mathrm{l}$ gentamicin, adjusted to $\mathrm{pH} 7.5$ with $\mathrm{NaOH}$.

Electrophysiological recordings. Prior to recording, oocytes were mechanically devitellinated under a stereoscope and placed in a recording chamber under an inverted IX71 microscope (Olympus, Tokyo, Japan) equipped with a $10 \times$ or $20 \times$ objective. Patch electrodes were pulled from $1.5 \mathrm{~mm}$ thick borosilicate glass capillaries (Hilgenberg, Malsfeld, Germany) on a DMZ puller (Zeitz Instruments GmbH, Martinsried, Germany) and subsequently fire polished with a Narishige MF-830 microforge (Narishige, Tokyo, Japan). The resulting initial electrode resistance was $0.6-1.5 \mathrm{M} \Omega$ (about 8-30 $\mu \mathrm{m}$ inner tip diameter) in the used recording solutions. Excised macro patches were obtained within seconds to minutes. Holding potentials were $-60 \mathrm{mV}$ or $-80 \mathrm{mV}$. Recordings were performed at room temperature (RT, 22-25 ${ }^{\circ} \mathrm{C}$ ) using an Axopatch $200 \mathrm{~B}$ amplifier (Molecular Devices, Union City, CA, USA), connected via a Digidata 1440A acquisition board (Molecular Devices) to a PC running the ClampEx software (Molecular Devices). Data were filtered at 2 or $5 \mathrm{kHz}$ and the sampling rate was $10 \mathrm{kHz}$. Pipette and bath solutions contained (in mM): 100 HEPES, 30 methanesulfonic acid, 5 tetraethylammonium chloride (TEA-Cl), and 5 EGTA, adjusted to $\mathrm{pH} 7.0$ or $\mathrm{pH} 7.5$ with TEA hydroxide $(>25 \mathrm{mM})$. HEPES was replaced by 2 -(N-morpholino)ethanesulfonic acid (MES) in recording solutions adjusted to $\mathrm{pH}$ 6.5. Large proton currents generated by the activation of proton channels can lead to accumulation or depletion of protons at either side of the membrane, thereby changing the $\mathrm{pH}$ in the vicinity of the proton channel ${ }^{29}$. As a consequence, the electrochemical driving force for protons can change (reduction of outward currents during channel activation), precluding stable recording conditions. In order to keep the $\mathrm{pH}$ during $\mathrm{Hv} 1$ activation as stable as possible, we used solutions with high $\mathrm{pH}$ buffer concentrations $(100 \mathrm{mM})$, used patch pipettes with large tip diameters to obtain a large $\mathrm{pH}$-buffer volume-to-membrane surface ratio, and used oocytes with low Hv1 expression levels to record rather small proton currents. Chemicals were purchased from Sigma-Aldrich (St. Louis, MO, USA), Carl Roth (Karlsruhe, Germany), Thermo Fisher Scientific Inc. (Waltham, MA, USA), Toronto Research Chemical (Toronto, ON, Canada), or Tocris (Bristol, UK).

PCF recordings. On the day of recording, oocytes were labeled at $4{ }^{\circ} \mathrm{C}$ for $45-60 \mathrm{~min}$ in a solution containing (in $\mathrm{mM}$ ): $92 \mathrm{KCl}, 0.75 \mathrm{CaCl}_{2}, 1 \mathrm{MgCl}_{2}, 10 \mathrm{HEPES}$, and 0.05 (2-((5)6)-Tetramethyl-rhodamine)carboxylamino)ethyl)methanethiosulfonate (MTS-TAMRA), adjusted to $\mathrm{pH} 7.5$ with $\mathrm{KOH}$. Subsequently, oocytes were washed three times in ND96 and stored at $12{ }^{\circ} \mathrm{C}$ until recording. Excised patches were obtained under visual control using a $10 \times$ objective. The objective was changed to a $60 \times$ oil-immersion objective (Olympus Apo $\mathrm{N}$ 60XOTIRF NA1.49 or PLAPON 60XOTIRFM NA 1.45). TAMRA was excited with a Spectra X (Lumencor, Beaverton, OR) at 550/15 nm or a Polychrome 5 light source (Till Photonics, Martinsried, Germany), and the fluorescence emission was monitored through a TRITC filter cube (Semrock, Rochester, NY, USA; excitation FF01-543/22-25, dichroic FF562-Di03, and emission FF01-593/40, or excitation FF01-542/20, dichroic FF570Di01, and emission FF01-620/52) and detected with an iXon Ultra DU-897U or a Luca S emCCD camera (iXon Ultra, Andor Technologies, Belfast, UK). The frame rate was $200 \mathrm{~Hz}, 8 \times 8$ pixels were binned and registered in the frame-transfer mode using the camera's conventional output amplifier. Acquisition was triggered externally via the ClampEx software. The light intensities, measured with a PS19Q sensor connected to a FieldMax-TOP power meter for visible light (Coherent, Dieburg, Germany) at the level of the recording stage, were $\sim 0.16 \mathrm{~mW} /$ $\mathrm{mm}^{2}$.

Uncaging of NPE-caged-proton. 1-(2-nitrophenyl)ethyl (NPE)-caged-proton (Tocris, Bristol, UK) was dissolved in DMSO and added to the pipette solution at a final concentration of $500 \mu \mathrm{M}$ (1\% DMSO), just prior to the experiment. The pipette solution contained (in mM): 0.1 HEPES, 90 NMDG, 30 methanesulfonic acid (MS), 5 TEA chloride, and 5 EGTA adjusted to $\mathrm{pH} 7.5$ with MS. NPE-caged-proton was photolysed with a UV LED (365 nm, Thorlabs, Newton, New Jersey, United States). The light stimulus was triggered by the pClamp software. The light intensity, measured with a power meter at the level of the recording stage, was $\sim 0.86 \mathrm{~mW} /$ 
A

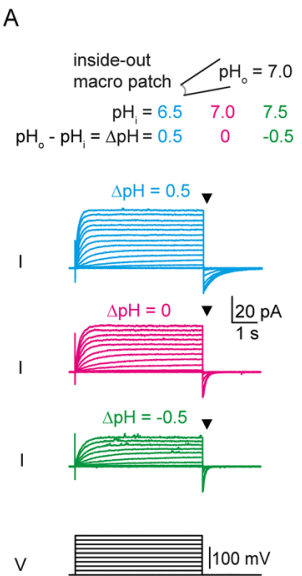

B
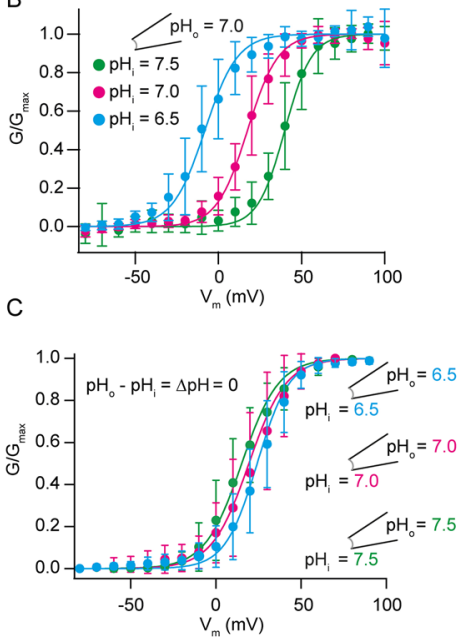

D

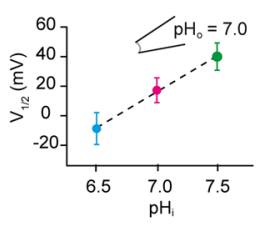

$\mathrm{F}$

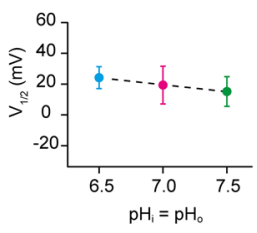

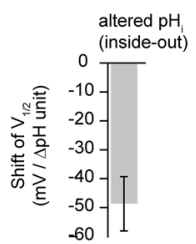

G

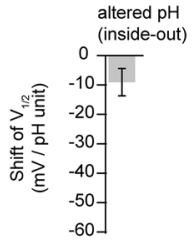

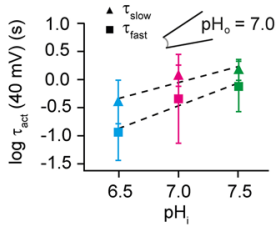

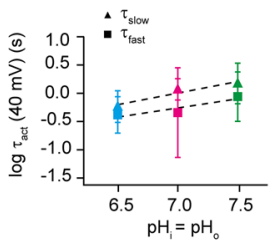

Figure 1. Voltage dependence of ciHv1 is coupled to the difference between $\mathrm{pH}_{\mathrm{i}}$ and $\mathrm{pH}_{\mathrm{o}}(\Delta \mathrm{pH})$, but not to $\mathrm{pH}$ itself. (A) inside-out patch-clamp recordings of ciHv1 at different $\Delta \mathrm{pH}$ conditions. (B) Mean GVs derived from tail currents (at time points specified by triangles in panel A) at different $\Delta \mathrm{pH}$ conditions. Data from individual patches were fitted with Boltzmann functions (not shown), and the resulting mean slopes and mean $\mathrm{V}_{1 / 2}$ values were used to construct Boltzmann fits for the mean GVs (see Table 1 for fit parameters). (C) GVs derived from tail currents of inside-out patch-clamp recordings of ciHv1 at different $\mathrm{pH}$, leaving $\Delta \mathrm{pH}=0$, fitted with Boltzmann functions. (D) $\mathrm{V}_{1 / 2}$ as a function of $\mathrm{pH}_{\mathrm{i}}$ while $\mathrm{pH}_{\mathrm{o}}=7$. The dashed line is a linear fit with a slope of $-48.6 \mathrm{mV} / \Delta \mathrm{pH}$ unit; $\mathrm{r}^{2}=0.8, p<0.05$. (E) shift of $\mathrm{V}_{1 / 2}$ per $\Delta \mathrm{pH}$ unit (altered $\mathrm{pH}_{\mathrm{i}},-48.6 \pm 9.5 \mathrm{mV}$ ). (F) $\mathrm{V}_{1 / 2}$ as a function of the $\mathrm{pH}$ itself. The dashed line is a linear fit with a slope of $-9.1 \mathrm{mV} / \mathrm{pH}$ unit; $\mathrm{r}^{2}=0.1$, n.s. (G), shift of $\mathrm{V}_{1 / 2}$ per $\mathrm{pH}$ unit $(-9.1 \pm 4.6 \mathrm{mV})$. $(\mathbf{H})$ activation time constants $\tau_{\text {fast }}$ and $\tau_{\text {slow }}$ as function of $\mathrm{pH}_{\mathrm{i}} \mathrm{while}_{\mathrm{pH}}=7$ (see also Table 2). The dashed lines are linear fits with $\operatorname{slope}\left(\tau_{\text {fast }}\right)=-0.8 \log (\mathrm{s}) / \Delta \mathrm{pH}$ unit, $\mathrm{r}^{2}=0.3, p<0.05$, and $\operatorname{slope}\left(\tau_{\text {slow }}\right)=-0.6 \log (\mathrm{s}) / \Delta \mathrm{pH}$ unit, $\mathrm{r}^{2}=0.4, p<0.05$. (I), activation time constants $\tau_{\text {fast }}$ and $\tau_{\text {slow }}$ as function of $\mathrm{pH}(\Delta \mathrm{pH}=0$, see also Table 2$)$. The dashed lines are linear fits with slope $\left(\tau_{\text {fast }}\right)=0.3 \log (\mathrm{s}) / \mathrm{pH}$ unit, $\mathrm{r}^{2}=0.2$, $p<0.05$, and slope $\left(\tau_{\text {slow }}\right)=0.4 \log (\mathrm{s}) / \mathrm{pH}$ unit, $\mathrm{r}^{2}=0.3, p<0.05$. Error bars indicate the SD.

$\mathrm{mm}^{2}$. In PCF experiments combined with uncaging, MTS-TAMRA was excited by a Spectra X light source at $550 / 15 \mathrm{~nm}$ and the emission filtered with two dichroic $562 \mathrm{LP}$ filter.

Data analysis. Data were analyzed with Igor Pro (Wavemetrics, Portland, OR, USA). Conductance-voltage relationships $(\mathrm{GV})$ were obtained from normalized tail currents $\left(\mathrm{I}_{\text {tail }}\right)$ measured 5-25 ms after the end of the depolarizing voltage step and fitted with the Boltzmann equation: $G / G_{\max }=1 /\left(1+\exp \left(-\left(V-V_{1 / 2}\right) / S\right)\right)$, where $\mathrm{G}_{\max }$ is the maximal conductance, $\mathrm{S}$ the slope, $\mathrm{V}$ the membrane voltage, and $\mathrm{V}_{1 / 2}$ the voltage at which $50 \%$ of the maximal amplitude is reached. From the PCF image frames, the mean (i.e. spatial average) fluorescence intensity was calculated from the brightest pixels (around 5-30 binned pixels, marked with stars in Fig. 2F), and the dark count of the camera was subtracted to obtain the fluorescence F. F was then normalized to the initial baseline level at $-80 \mathrm{mV}$ to obtain $\Delta \mathrm{F} / \mathrm{F}$. For the average fluorescence traces in different $\mathrm{pH}$ conditions (Figs. 2G, 3B, 5C and $6 \mathrm{~B}$ ), only traces in steady-state conditions (i.e. when solution exchange was completed) were used. The voltage-induced change in fluorescence is denoted as $\mathrm{F}_{\text {signal }}$, and the amplitude of $\mathrm{F}_{\text {signal }}$ is reported as the difference between the fluorescence at $-80 \mathrm{mV}$ and the steady-state fluorescence at the end of the voltage step. Activation time constants of current (I) and fluorescence (F) were obtained from double-exponential fits, and the deactivation time constants of $\mathrm{F}$ were obtained from mono-exponential fits. The minimum of $\mathrm{F}$ was taken as starting point for the deactivation. The relationship between voltage dependence or kinetics and $\mathrm{pH}$ or $\Delta \mathrm{pH}$ was tested with linear regression analysis and tested for significant deviations from a zero-slope line with a significance level of $\alpha=0.05$. For ciHv1-I175C-TAMRA, the $\Delta \mathrm{pH}$ dependence of fast and slow activation time constants of $\mathrm{F}$ was compared to the respective slopes of fast and slow activation time constants of I by two-tailed paired tests with a significance level of $\alpha=0.05 . \mathrm{r}^{2}$ denotes the coefficient of determination. The $\Delta \mathrm{pH}$-induced effects on the $\mathrm{F}_{\text {signal }}$ amplitude and $\mathrm{F}(-80 \mathrm{mV})$ were tested with one-way ANOVA, followed by Tukey's test post-hoc analysis. All values are reported as mean \pm SD.

\section{Results}

Voltage dependence of Hv1 is sensitive to $\Delta \mathrm{pH}$, but not to $\mathrm{pH}$ itself. To study the coupling between voltage- and $\Delta \mathrm{pH}$-sensing, we heterologously expressed Hv1 from Ciona intestinalis (ciHv1) in Xenopus laevis oocytes. CiHv1 displays robust heterologous expression ${ }^{18}$ and faster activation kinetics than human Hv1, which facilitates data acquisition. Hv1 currents were recorded from excised inside-out membrane patches under various $\mathrm{pH}$ conditions (Fig. 1). Voltage steps of increasing amplitudes (up to $+100 \mathrm{mV}$ ) gave rise to outward currents (Fig. 1A). From the tail currents (Fig. 1A, arrows), the normalized conductance-voltage relationship (GV) was calculated (Fig. 1B, see methods). We tested the action of $\Delta \mathrm{pH}$ on the GV relation by changing $\mathrm{pH}_{\mathrm{i}}$. 


\begin{tabular}{|c|c|c|c|c|c|}
\hline Channel & $\mathrm{V}_{1 / 2}$ shift/ $\Delta \mathrm{pH}$ unit $(\mathrm{mV})$ & $\mathrm{pH}_{\mathrm{i}} / \mathrm{pH}_{\mathrm{o}}$ & $\mathrm{V}_{1 / 2}(\mathrm{mV})$ & Slope $(\mathrm{mV})$ & $\mathbf{n}$ \\
\hline \multirow{5}{*}{ ciHv1 } & \multirow{5}{*}{$-48.6 \pm 9.5$} & $6.5 / 7.0$ & $-8.2 \pm 10.7$ & $9.8 \pm 2.5$ & 16 \\
\hline & & $7.0 / 7.0$ & $17.5 \pm 8.0$ & $9.2 \pm 3.0$ & 17 \\
\hline & & $7.5 / 7.0$ & $39.9 \pm 9.0$ & $8.1 \pm 3.3$ & 16 \\
\hline & & $6.5 / 6.5$ & $24.2 \pm 7.1$ & $9.4 \pm 2.4$ & 6 \\
\hline & & $7.5 / 7.5$ & $15.1 \pm 9.6$ & $10.8 \pm 1.8$ & 5 \\
\hline \multirow{3}{*}{$\begin{array}{l}\text { ciHv1-L245C- } \\
\text { TAMRA }\end{array}$} & \multirow{3}{*}{$-54.1 \pm 4.8$} & $6.5 / 7.0$ & $-50.5 \pm 9.5$ & $7.6 \pm 1.9$ & 5 \\
\hline & & $7.0 / 7.0$ & $-7.0 \pm 12.2$ & $7.4 \pm 2.1$ & 8 \\
\hline & & $7.5 / 7.0$ & $-2.5 \pm 13.7$ & $6.9 \pm 2.2$ & 7 \\
\hline
\end{tabular}

Table 1. Fit parameters of the GV relationships of ciHv1 and ciHv1-L245C-TAMRA (mean \pm SD).

\begin{tabular}{|c|c|c|c|}
\hline $\mathrm{pH}_{\mathrm{i}} / \mathrm{pH}_{\mathrm{o}}$ & $\tau_{\text {fast }}(\mathbf{s})$ & $\tau_{\text {slow }}(\mathrm{s})$ & $\mathbf{n}$ \\
\hline $6.5 / 7.0$ & $0.16 \pm 0.08$ & $0.54 \pm 0.44$ & 7 \\
\hline $7.0 / 7.0$ & $0.87 \pm 0.69$ & $1.28 \pm 0.55$ & 9 \\
\hline $7.5 / 7.0$ & $1.03 \pm 0.63$ & $1.58 \pm 0.52$ & 6 \\
\hline $6.5 / 6.5$ & $0.49 \pm 0.23$ & $0.71 \pm 0.36$ & 9 \\
\hline $7.5 / 7.5$ & $1.19 \pm 0.83$ & $1.85 \pm 1.08$ & 5 \\
\hline
\end{tabular}

Table 2. Activation kinetics ( $\tau_{\text {fast }}$ and $\tau_{\text {slow }}$ ) of the current of ciHv1 during a voltage step to $40 \mathrm{mV}$ at different $\mathrm{pH}_{\mathrm{i}}$ and $\mathrm{pH}_{\mathrm{o}}($ mean $\pm \mathrm{SD})$.

When $\mathrm{pH}_{\mathrm{i}}$ was changed from 7.0 to $6.5(\Delta \mathrm{pH}=0.5)$ or from 7.0 to $7.5(\Delta \mathrm{pH}=-0.5)$, the voltage of half-maximal activation $\left(\mathrm{V}_{1 / 2}\right)$ of the $\mathrm{GV}$ relation shifted towards more negative or positive potentials, respectively (Fig. 1B). Similar to previous reports ${ }^{1,2,24}$, the $\mathrm{V}_{1 / 2}$ shifted by $-48.6 \pm 9.5 \mathrm{mV} / \Delta \mathrm{pH}$ unit (Fig. 1D,E, Table 1). By contrast, at symmetrical $\mathrm{pH}(\Delta \mathrm{pH}=0), \mathrm{V}_{1 / 2}$ shifted only by $-9.1 \pm 4.6 \mathrm{mV} / \mathrm{pH}$ unit between $\mathrm{pH} 6.5$ and 7.5 (Fig. 1C,F,G), indicating that within this $\mathrm{pH}$ range, the voltage dependence of ciHv1, like the voltage dependence of its orthologues from human and mice, is relatively insensitive to $\mathrm{pH}$ itself (Fig. $1 \mathrm{G}$ ). Similar to the $\Delta \mathrm{pH}$-dependent changes in kinetics seen in voltage-gated proton currents in rat alveolar epithelial cells ${ }^{24}$, we also find $\Delta \mathrm{pH}$ dependent activation kinetics of ciHvl: the fast and slow activation time constants $\tau_{\text {fast }}$ and $\tau_{\text {slow }}$ become faster when $\Delta \mathrm{pH}$ becomes more positive, i.e. when $\mathrm{pH}_{\mathrm{i}}<\mathrm{pH}_{\mathrm{o}}$ (Fig. $1 \mathrm{H}$, Table 2). The relationship between $\log \left(\tau_{\text {fast }}\right)$ and $\Delta \mathrm{pH}$, and between $\log \left(\tau_{\text {slow }}\right)$ and $\Delta \mathrm{pH}$ was linear in the investigated range. As previously reported for human $\mathrm{Hv}_{1}^{30}$, we also find that the activation time constants of ciHv1 are faster at acidic symmetric $\mathrm{pH}$ than at alkaline symmetric $\mathrm{pH}$ (Fig. 1I and Table 2). However, the dependence of channel activation kinetics on $\Delta \mathrm{pH}$ is steeper than the dependence of channel activation kinetics on symmetric changes in $\mathrm{pH}$ itself (compare Fig. 1H,I). Taken together, the activation kinetics suggest that channel gating depends more on $\mathrm{pH}_{\mathrm{i}}$ than on $\mathrm{pH}_{\mathrm{o}}$.

The motion of the $\mathbf{S 4}$ segment is similar for different symmetric $\mathrm{pH}$ conditions. To identify the molecular mechanism of coupling between voltage- and $\Delta \mathrm{pH}$-sensing, we studied the underlying conformational changes of Hv1. Previous studies showed that S4 is the main voltage sensor that moves outwardly upon depolarization ${ }^{18,19,22}$. Here, using the PCF technique ${ }^{22,31,32}$, we investigated whether altering $\Delta \mathrm{pH}$ alone can change the $\mathrm{S} 4$ conformation. As readout for conformational changes, we used the thiol-reactive fluorophore MTS-TAMRA (Fig. 2A). TAMRA is environmentally sensitive: the fluorescence intensity in a polar solvent, like $\mathrm{H}_{2} \mathrm{O}$, is lower compared to that in a less polar solvent, like ethanol or methanol (Fig. 2B). This property has been used to track conformational changes of ion channels ${ }^{19,33,34}$. By contrast, TAMRA is insensitive to changes in $\mathrm{pH}$ : aqueous solutions of pH 6.5 to 7.5 do not change the fluorescence intensity (Fig. 2B). Thus, TAMRA is suitable to track protein conformational changes at different $\mathrm{pH}$.

For MTS-TAMRA labeling, a single cysteine was introduced at position L245C, which is located at the extracellular end of $4^{35}$ (Fig. 2C); this site corresponds to F195C used for labeling of human Hv1 ${ }^{19}$. The dependence of $\mathrm{V}_{1 / 2}$ on $\Delta \mathrm{pH}$ in this labelled mutant, called ciHv1-L245C-TAMRA, is preserved (Fig. 2D and Table 1). Fluorescence in voltage-clamped, excised inside-out macro-patches was recorded (excitation light: $550 \mathrm{~nm}$ ) with a camera (Fig. 2E). The membrane patch was visible as a curved fluorescent stripe (Fig. 2F). Pixels were binned to allow for fast frame rates $(200 \mathrm{~Hz})$, and voltage-evoked changes in the fluorescence of the membrane patch $(\Delta \mathrm{F})$ were analyzed. A previous study using voltage-clamp fluorometry identified complex voltage-evoked fluorescence signals that were interpreted as two consecutive S4 conformational changes that lead to Hv1 channel opening ${ }^{36}$. Here, we probed $\mathrm{S} 4$ conformational changes by stepping from -80 to -40 or $+40 \mathrm{mV}$ such that the Hv1 channels preferentially populate the activated closed state or the activated open state, respectively. Upon a voltage step from a holding potential of -80 to $-40 \mathrm{mV}$ (activated closed state), the fluorescence of ciHv1-L245C-TAMRA decreased. The change was reversible: upon stepping back to $-80 \mathrm{mV}$, the fluorescence intensity returned to its original value (Fig. $2 \mathrm{G}$, left). This voltage-evoked fluorescence signal $\left(\mathrm{F}_{\text {signal }}\right)$ is consistent with a previous study ${ }^{36}$ 
A

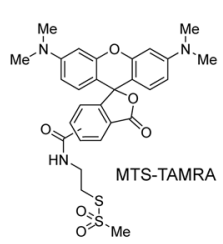

B

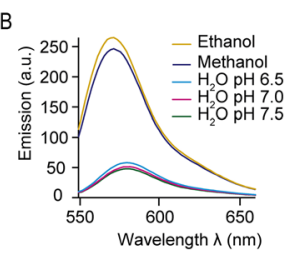

$\mathrm{H}$

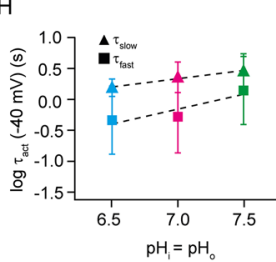

C

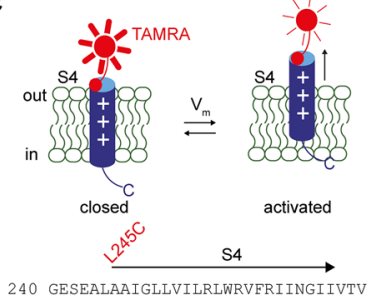

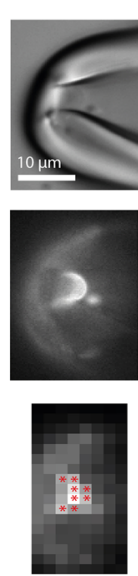

$\mathrm{G}$
$\Delta \mathrm{F}$
$\mathrm{I}$
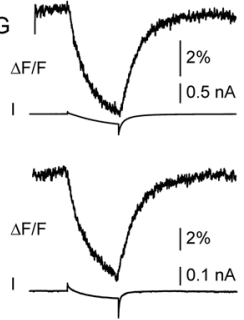

E

D

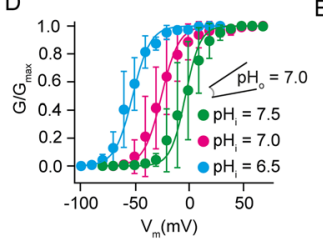

I

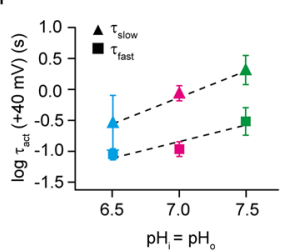

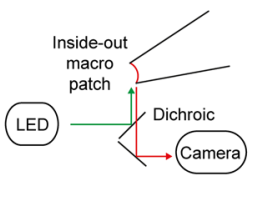

$\mathrm{J}$

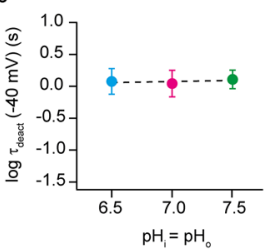

$\mathrm{K}$

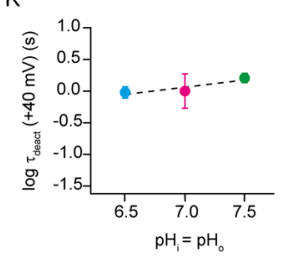

Figure 2. PCF recordings at the extracellular end of $\mathrm{S} 4$ for different symmetric $\mathrm{pH}$ conditions. (A) chemical structure of MTS-TAMRA. (B) emission spectrum of MTS-TAMRA (50 nM) in ethanol, methanol, and aqueous solutions buffered to various $\mathrm{pH}$ values. Excitation wavelength was $542 \mathrm{~nm}$. (C) top, cartoon depicting voltage-evoked S4 conformational change of ciHv1-L245C-TAMRA. For clarity, only S4 is shown. " + "signs denote the charged arginines in S4. Bottom, amino-acid sequence of the S4 voltage sensor of ciHv1 and the site of labeling. (D) GVs derived from tail currents of inside-out patch-clamp recordings of ciHv1-L245C-TAMRA at different $\Delta \mathrm{pH}$ conditions, fitted with Boltzmann functions (see Table 1 for fit parameters). (E) scheme of the inside-out PCF recording condition. (F) excised inside-out patch containing ciHv1-L245C-TAMRA (top, bright-field image; middle, epifluorescent image; bottom, $8 \times 8$-binned epifluorescent image). Red stars mark pixels included in analysis. (G) representative inside-out PCF recordings of ciHv1-245C-TAMRA, in response to voltage steps from -80 to -40 (left) or $+40 \mathrm{mV}$ (right) at different $\mathrm{pH}$ conditions leaving $\Delta \mathrm{pH}=0$. The fluorescence $(\Delta \mathrm{F} / \mathrm{F})$ is the spatial average of the pixel intensities of the marked pixels as exemplified in panel $\mathrm{F}$ (bottom, see Methods). ( $\mathbf{H}-\mathbf{I})$, mean activation time constants $\tau_{\text {fast }}$ and $\tau_{\text {slow }}$ of $\mathrm{F}_{\text {signal }}$ at $-40 \mathrm{mV}$ (panel $\mathrm{H}$ ) or $+40 \mathrm{mV}$ (panel I) as a function of $\mathrm{pH}$ (see also Table 3). The dashed lines are linear fits with the following slopes: $\operatorname{slope}\left(\tau_{\text {fast }}\right)=0.5 \log (\mathrm{s}) / \mathrm{pH}$ unit, $\mathrm{r}^{2}=0.2$, n.s., and $\operatorname{slope}\left(\tau_{\text {slow }}\right)=0.3 \log (\mathrm{s}) / \mathrm{pH}$ unit, $\mathrm{r}^{2}=0.1, \mathrm{n}$. ., at $-40 \mathrm{mV}$; $\operatorname{slope}\left(\tau_{\text {fast }}\right)=0.5 \log (\mathrm{s}) / \mathrm{pH}$ unit, $\mathrm{r}^{2}=0.6, p<0.05$ and slope $\left(\tau_{\text {slow }}\right)=0.9 \log (\mathrm{s}) / \mathrm{pH}$ unit, $\mathrm{r}^{2}=0.5, p<0.05$, at $+40 \mathrm{mV}$. $(\mathrm{J}-\mathrm{K})$ mean deactivation time constants $\tau_{\text {deact }}$ of $\mathrm{F}_{\text {Signal }}$ during repolarization from $-40 \mathrm{mV}$ (panel J) or $+40 \mathrm{mV}$ (panel $\mathrm{K}$ ) to $-80 \mathrm{mV}$ as function of $\mathrm{pH}$ (see also Table 3). The dashed lines are linear fits with the following slopes: $\operatorname{slope}\left(\tau_{\text {deact }}\right)=0.03 \log (\mathrm{s}) / \mathrm{pH}$ unit, $\mathrm{r}^{2}=0.005$, n.s., for $-40 \mathrm{mV} ; \operatorname{slope}\left(\tau_{\text {deact }}\right)=0.2 \log (\mathrm{s}) / \mathrm{pH}$ unit, $\mathrm{r}^{2}=0.3$, n.s., for $+40 \mathrm{mV}$. Error bars indicate the SD.

and was interpreted as the initial outward $\mathrm{S} 4$ motion during voltage sensing. $\mathrm{F}_{\text {signal }}$ is similar in overall shape for various symmetric $\mathrm{pH}$ conditions $\left(\mathrm{pH}_{\mathrm{i}}=\mathrm{pH}_{\mathrm{o}}=6.5,7.0\right.$, or 7.5 , thus $\Delta \mathrm{pH}=0$; Fig. 2G, left). The activation kinetics tend to be faster in acidic conditions; the differences were, however, not significant (Fig. $2 \mathrm{H})$. Likewise, the deactivation kinetics do not depend on the $\mathrm{pH}$ itself (Fig. 2J).

A voltage step from a holding potential of -80 to $+40 \mathrm{mV}$ (activated open state) led to a more complex $\mathrm{F}_{\text {signal }}$ : a biphasic decrease of the fluorescence intensity. In addition, upon stepping back to $-80 \mathrm{mV}$, the fluorescence further decreased and then returned back to baseline, producing a characteristic "hook" in the fluorescence (Fig. 2G, right). Such an $\mathrm{F}_{\text {signal }}$ was also observed in a previous study ${ }^{36}$ and was interpreted as the result of voltagedependent Hvl channel activation from a resting closed state (high fluorescence intensity) via an activated closed state (low fluorescence intensity) to an activated open state (intermediate fluorescence intensity). Like $\mathrm{F}_{\text {signal }}$ at $-40 \mathrm{mV}, \mathrm{F}_{\text {signal }}$ at $+40 \mathrm{mV}$ is similar in overall shape at various symmetric $\mathrm{pH}$ conditions $\left(\mathrm{pH}_{\mathrm{i}}=\mathrm{pH}_{\mathrm{o}}=6.5\right.$, 7.0, or 7.5; thus $\Delta \mathrm{pH}=0$; Fig. 2G, right). However, some kinetics change for different symmetric $\mathrm{pH}$ conditions: at $+40 \mathrm{mV}$, but not at $-40 \mathrm{mV}$, the fast and slow activation kinetics of $\mathrm{F}_{\text {signal }}$ are significantly faster at acidic than at alkaline $\mathrm{pH}$ (Fig. 2H,I, Table 3). This might suggest that the transition of the intermediate to the open state is dependent on the $\mathrm{pH}$ itself. Interestingly, it has been predicted for human Hv1 that intermediate states are particularly dependent on $\mathrm{pH}_{\mathrm{i}}{ }^{37}$. The deactivation kinetics did not change for different symmetric $\mathrm{pH}$ conditions (Fig. 2J,K, Table 3). By stepping from $-80 \mathrm{mV}$ to $-40 \mathrm{mV}$, small inward currents were elicited, which indicates channel opening. However, $\mathrm{F}_{\text {signal }}$ lacked the characteristic "hook" (Fig. 2G, left and Fig. 3A, B), suggesting that $\mathrm{F}_{\text {signal }}$ evoked by a voltage step to $-40 \mathrm{mV}$ mainly reports on closed-state channel transitions. This is supported 


\begin{tabular}{|l|l|l|l|l|l|}
\hline $\mathbf{p H}_{\mathrm{i}} / \mathbf{p H}_{\mathbf{o}}$ & Voltage & $\boldsymbol{\tau}_{\text {fast }}(\mathbf{s})$ & $\boldsymbol{\tau}_{\text {slow }}(\mathbf{s})$ & $\boldsymbol{\tau}_{\text {deact }}(\mathbf{s})$ & $\mathbf{n}$ \\
\hline \multirow{3}{*}{$6.5 / 6.5$} & $-40 \mathrm{mV}$ & $0.77 \pm 0.69$ & $1.61 \pm 0.56$ & $1.28 \pm 0.48$ & 5 \\
\cline { 2 - 6 } & $+40 \mathrm{mV}$ & $0.09 \pm 0.02$ & $0.38 \pm 0.26$ & $0.97 \pm 0.21$ & 3 \\
\hline \multirow{3}{*}{$7.0 / 7.0$} & $-40 \mathrm{mV}$ & $1.04 \pm 1.22$ & $2.67 \pm 1.83$ & $1.22 \pm 0.59$ & 9 \\
\cline { 2 - 6 } & $+40 \mathrm{mV}$ & $0.11 \pm 0.03$ & $0.89 \pm 0.25$ & $1.16 \pm 0.78$ & 4 \\
\hline \multirow{2}{*}{$7.5 / 7.5$} & $-40 \mathrm{mV}$ & $2.48 \pm 2.37$ & $3.45 \pm 2.32$ & $1.35 \pm 0.47$ & 9 \\
\cline { 2 - 6 } & $+40 \mathrm{mV}$ & $0.33 \pm 0.13$ & $2.34 \pm 1.53$ & $1.62 \pm 0.28$ & 4 \\
\hline
\end{tabular}

Table 3. Activation $\left(\tau_{\text {fast }}, \tau_{\text {slow }}\right)$ and deactivation $\left(\tau_{\text {deact }}\right)$ kinetics of the $\mathrm{F}_{\text {signal }}$ of ciHv1-L245C-TAMRA during a voltage step to -40 or $+40 \mathrm{mV}$ at different symmetric $\mathrm{pH}(\Delta \mathrm{pH}=0$; mean $\pm \mathrm{SD})$.

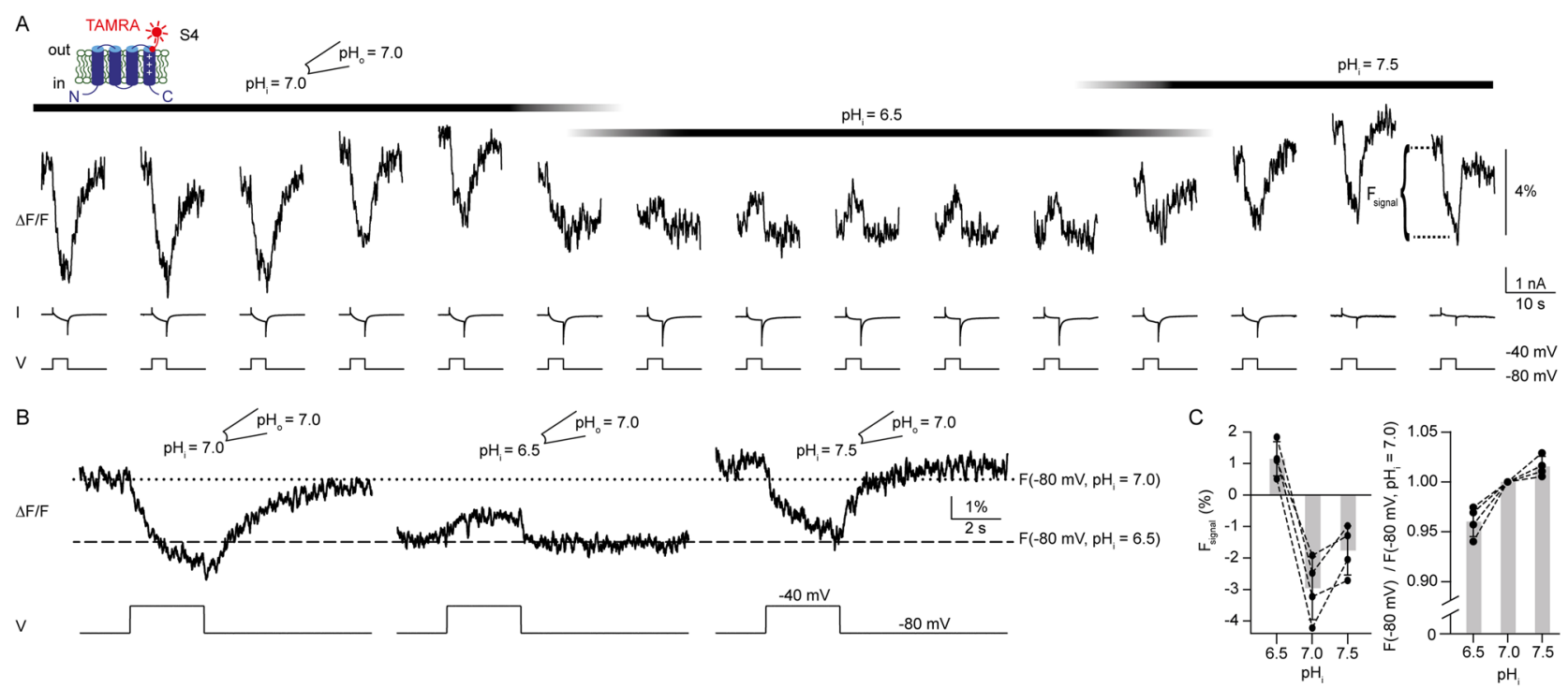

Figure 3. Changes in $\triangle \mathrm{pH}$ induce $\mathrm{S} 4$ conformational changes. (A) representative inside-out PCF recording of ciHv1-L245C-TAMRA in response to repetitive voltage steps from $-80 \mathrm{mV}$ to $-40 \mathrm{mV}$ and back while changing $\mathrm{pH}_{\mathrm{i}}$ and keeping $\mathrm{pH}_{\mathrm{o}}=7.0$. The voltage-evoked fluorescence signal is denoted as $\mathrm{F}_{\text {signal. }}$. (B) mean fluorescence signals calculated from (A) for different $\mathrm{pH}_{\mathrm{i}}$ while $\mathrm{pH}_{\mathrm{o}}=7.0$. Horizontal lines (dotted, $\mathrm{pH}_{\mathrm{i}}=7.0$; dashed, $\left.\mathrm{pH}_{\mathrm{i}}=6.5\right)$ indicate the average fluorescence at $-80 \mathrm{mV}$. (C) left, amplitude of $\mathrm{F}_{\text {signal }}$ as a function of $\mathrm{pH}_{\mathrm{i}}$ while $\mathrm{pH}_{\mathrm{o}}=7.0(\mathrm{n}=4$ patches from 4 different cells $)$. For $\mathrm{pH}_{\mathrm{i}}=6.5, \mathrm{~F}_{\text {signal }}=1.1 \pm 0.5$; for $\mathrm{pH}_{\mathrm{i}}=7.0, \mathrm{~F}_{\text {signal }}=-$ $3.0 \pm 1.0$; for $\mathrm{pH}_{\mathrm{i}}=7.5, \mathrm{~F}_{\text {signal }}=-1.8 \pm 0.8$; one-way ANOVA, $p<0.001$; post-hoc analysis: $\mathrm{F}_{\text {signal }}$ for $\mathrm{pH}_{\mathrm{i}}=7.0$ vs. $\mathrm{F}_{\text {signal }}$ for $\mathrm{pH}_{\mathrm{i}}=6.5: p=0.0001 ; \mathrm{F}_{\text {signal }}$ for $\mathrm{pH}_{\mathrm{i}}=7.0$ vs. $\mathrm{F}_{\text {signal }}$ for $\mathrm{pH}_{\mathrm{i}}=7.5: p=0.1 ; \mathrm{F}_{\text {signal }}$ for $\mathrm{pH}_{\mathrm{i}}=6.5$ vs. $\mathrm{F}_{\text {signal }}$ for $\left.\mathrm{pH}_{\mathrm{i}}=7.5: p=0.002\right)$. Right, baseline fluorescence at $-80 \mathrm{mV}(\mathrm{F}(-80 \mathrm{mV}))$ as a function of $\mathrm{pH}_{\mathrm{i}}$ while $\mathrm{pH}_{\mathrm{o}}=7.0$, normalized to $\mathrm{F}(-80 \mathrm{mV})$ at $\mathrm{pH}_{\mathrm{i}}=7.0\left(\mathrm{n}=4\right.$ patches from 4 different cells). For $\mathrm{pH}_{\mathrm{i}}=6.5, \mathrm{~F}(-$ $80 \mathrm{mV})=0.96 \pm 0.02$; for $\mathrm{pH}_{\mathrm{i}}=7.5, \mathrm{~F}(-80 \mathrm{mV})=1.02 \pm 0.01$; one-way ANOVA: $p<0.001$; post-hoc analysis: $\mathrm{F}(-80 \mathrm{mV})$ for $\mathrm{pH}_{\mathrm{i}}=7.0$ vs. $\mathrm{F}(-80 \mathrm{mV})$ for $\mathrm{pH}_{\mathrm{i}}=6.5, p=0.001 ; \mathrm{F}(-80 \mathrm{mV})$ for $\mathrm{pH}_{\mathrm{i}}=7.0 \mathrm{vs}$. $\mathrm{F}(-80 \mathrm{mV})$ for $\mathrm{pH}_{\mathrm{i}}=7.5, p=0.15 ; \mathrm{F}(-80 \mathrm{mV})$ for $\mathrm{pH}_{\mathrm{i}}=6.5 \mathrm{vs}$. $\mathrm{F}(-80 \mathrm{mV})$ for $\mathrm{pH}_{\mathrm{i}}=7.5, p<0.001$. Error bars indicate the SD.

by the opening probability of around 0.2 for $\Delta \mathrm{pH}=0$ at $-\mathrm{mV}$ (Fig. 2D), meaning that $20 \%$ of the channels were opened and $80 \%$ of the channels remained in a non-conducting state.

Motion of the S4 segment is sensitive to changes in $\Delta \mathrm{pH}$. We next tested whether changes in $\Delta \mathrm{pH}$ affect the voltage-dependent motion of the $\mathrm{S} 4$ voltage sensor. While recording from an excised inside-out patch containing ciHv1-L245C-TAMRA, we changed $\Delta \mathrm{pH}$ by switching to solutions of different $\mathrm{pH}_{\mathrm{i}}$, whereas $\mathrm{pH}_{\mathrm{o}}$ was kept constant (7.0), and repetitively stepped from $-80 \mathrm{mV}$ to $-40 \mathrm{mV}$ and back (Fig. 3A). For clarity, averages of the amplitudes of $\mathrm{F}_{\text {signal }}$ from Fig. 3A are summarized in Fig. 3B. When a more acidic solution was washed in $\left(\mathrm{pH}_{\mathrm{i}}=6.5, \Delta \mathrm{pH}=0.5\right)$, the fluorescence under symmetric $\mathrm{pH}$ conditions $\left(\mathrm{pH}_{\mathrm{i}}=\mathrm{pH}_{\mathrm{o}}=7, \Delta \mathrm{pH}=0\right)$ was drastically altered in several aspects: first, the baseline fluorescence intensity was lowered at $-80 \mathrm{mV}$, indicating that changes in $\Delta \mathrm{pH}$ affect the $\mathrm{S} 4$ conformation in a non-conducting closed state (Fig. 3A, B). Second, the voltage step to $-40 \mathrm{mV}$ induced an increase rather than a decrease of the amplitude of $\mathrm{F}_{\text {signal }}$ compared to the $\Delta \mathrm{pH}=0$ condition; upon stepping back to $-80 \mathrm{mV}$, the fluorescence returned to baseline fluorescence intensity (Fig. 3A, B). At more alkaline $\mathrm{pH}_{\mathrm{i}}\left(\mathrm{pH}_{\mathrm{i}}=7.5, \Delta \mathrm{pH}=-.5\right)$, the baseline fluorescence and $\mathrm{F}_{\text {signal }}$ resembled those under $\Delta \mathrm{pH}=0$ conditions (Fig. $3 \mathrm{~A}, \mathrm{~B}$ ). In Fig. $3 \mathrm{C}$, the mean amplitudes of $\mathrm{F}_{\text {ignal }}$ (left) and the normalized baseline fluorescence $(\mathrm{F}(-80 \mathrm{mV})$, right) at different $\Delta \mathrm{pH}$ are summarized. Taken together, this data indicates that changes 
A

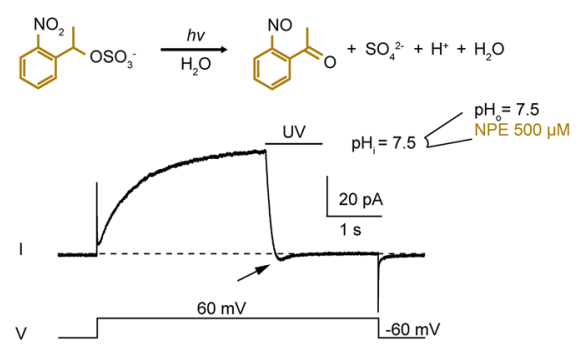

C

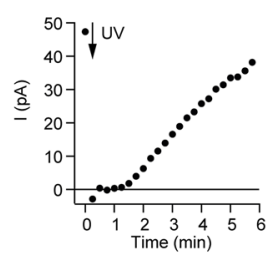

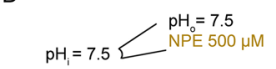

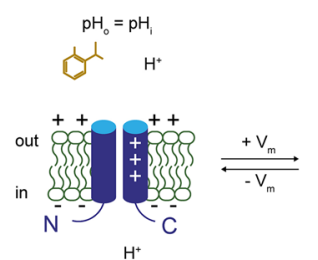

$\mathrm{H}^{+}$

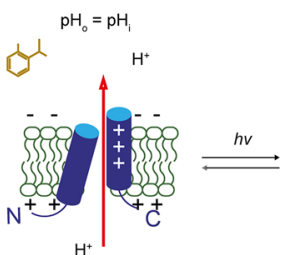

E

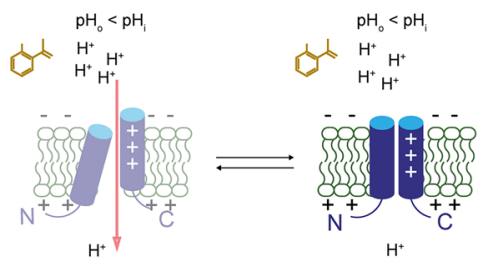

$\mathrm{F}$
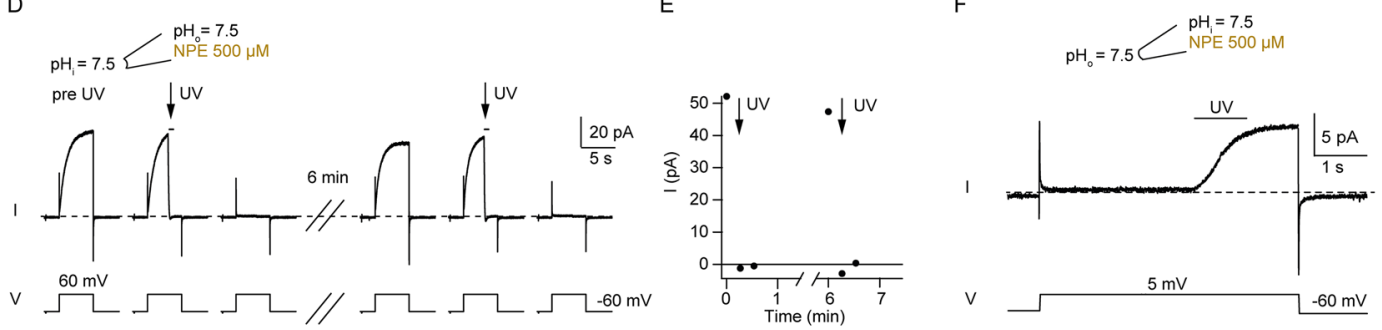

Figure 4. Proton uncaging rapidly and transiently acidifies the pipette solution at the membrane patch. (A) top, chemical structure and uncaging reaction of NPE-caged-proton. Bottom, representative inside-out patchclamp recording of ciHv1 in response to a voltage step from $-60 \mathrm{mV}$ to $+60 \mathrm{mV}$. UV light was applied for $1 \mathrm{~s}$. The patch pipette contained $500 \mu \mathrm{M}$ NPE-caged-proton buffered to $\mathrm{pH}_{\mathrm{o}}=7.5$ with $0.1 \mathrm{mM}$ HEPES, while the bath solution was buffered to $\mathrm{pH}_{\mathrm{i}}=7.5$ with 100 mM HEPES. (B) gating scheme of ciHv1. For clarity, only S1 and S4 are shown. "+" signs denote the charged arginines in S4. Red arrows indicate the direction of proton current. (C) current amplitude of an inside-out patch-clamp recording in response to repetitive voltage steps as in A over time (time point indicated by arrow in A). Arrow indicates light stimulus (iteration shown in A). (D) representative inside-out patch-clamp recording of ciHv1 in response to voltage steps from $-60 \mathrm{mV}$ to + $60 \mathrm{mV}$. UV-light stimulation was applied twice to the same patch as indicated by the arrows; the pause between stimulations was approximately $6 \mathrm{~min}$. (E) maximal outward current amplitude of the recording in D over time. Arrows indicate iterations with light stimulus. (F) representative outside-out patch-clamp recording of ciHv1 in response to a voltage step from $-50 \mathrm{mV}$ to $+5 \mathrm{mV}$ and $-60 \mathrm{mV}$. UV light was applied for $1 \mathrm{~s}$. The patch pipette contained $500 \mu \mathrm{M}$ NPE-caged-proton at $\mathrm{pH}_{\mathrm{i}}=7.5$, buffered with $0.1 \mathrm{mM}$ HEPES; $\mathrm{pH}_{\mathrm{o}}$ was 7.5 , buffered with 100 mM HEPES.

in $\mathrm{pH}_{\mathrm{i}}$ that introduce a $\Delta \mathrm{pH}>0$ can alter the $\mathrm{S} 4$ conformation in a non-conducting state, suggesting that the S4 conformation is not only sensitive to the membrane potential, but also sensitive to changes in $\Delta \mathrm{pH}$.

Proton uncaging in the patch pipette transiently alters $\mathrm{pH}$. So far, we exchanged the $\mathrm{pH}$ in the recording chamber by exchanging solution using a gravity-driven perfusion system connected to the recording chamber (Figs. 1B, 2D, 3A). While the exchange of solutions in patch pipettes during a recording is also possible $^{38}$, it is relatively slow and likely to be incomplete. To change the $\mathrm{pH}$ (i.e. lower the $\mathrm{pH}$ ) in the patch pipette during a recording rapidly and without solution exchange (which can introduce artifacts), we used the photolytically cleavable cage 1-(2-nitrophenyl)ethyl sulfate (NPE-caged-proton). NPE-caged-proton releases a sulfate and a proton upon UV irradiation ${ }^{39}$ (Fig. 4A). We tested UV-light induced acidification by uncaging NPE-caged-proton at the extracellular side in excised inside-out patches containing ciHv1. Prior to UV light, robust outward proton currents were recorded in response to voltage steps from - 60 to $+60 \mathrm{mV}$ (Fig. 4A). During depolarization, a 1-s long UV-light stimulus first rapidly diminished the outward current, then led to a brief and small inward current, and finally abolished the current (Fig. 4A). The recording is consistent with a UVlight induced extracellular acidification (and hence a change in the electrochemical driving force for protons) and the coupled $\Delta \mathrm{pH}$ - and voltage-sensing of Hv1, as depicted in Fig. 4B: depolarization to $+60 \mathrm{mV}$ opens the proton channels and leads to a proton outward current (Transition 1). UV-light induced extracellular acidification changes the electrochemical driving force for protons to such an extent $(\Delta \mathrm{pH}<-1)$ that the proton current reverses direction (Transition 2 , indicated by arrow in Fig. $4 \mathrm{~A}$ ). The negative $\Delta \mathrm{pH}$ also closes the proton channels (Transition 3), implying that the open state of ciHvl is also sensitive to $\Delta \mathrm{pH}$. Thus, it is indeed possible to change the $\mathrm{pH}$ in the patch pipette during recording. Subsequent depolarizing voltage steps immediately after UV-light application did not elicit proton currents (Fig. 4C). After several minutes, however, the proton-current amplitude recovered (Fig. $4 \mathrm{C}$ ), showing that the initial $\mathrm{pH}$ at the extracellular side of the membrane (facing the lumen of the patch pipette) is reestablished. This suggests that proton uncaging took predominantly place locally in the direct vicinity of the patch membrane (in the focal plane where UV-light intensity is maximal) and not in the bulk volume of the patch pipette, and that subsequent diffusion of buffer and protons reestablishes the initial $\mathrm{pH}$. If this is the case, NPE-caged-protons should diffuse from the bulk volume back to the vicinity of the patch membrane and allow further local uncaging. Indeed, after several minutes, a second UV-light application could again diminish the proton current (Fig. 4D, E). This also shows that the UV-light stimulus does not degrade the functionality of the ciHvl proton channel. Next, we tested UV-light induced acidification 
A

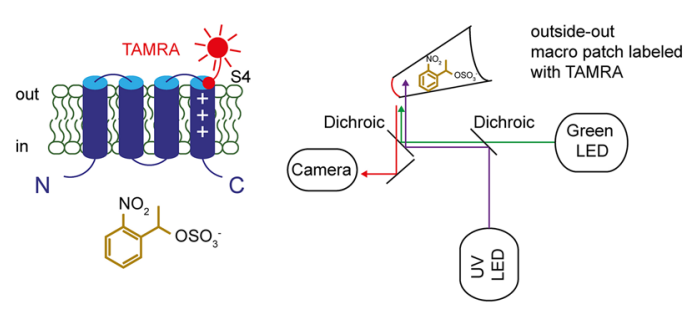

C

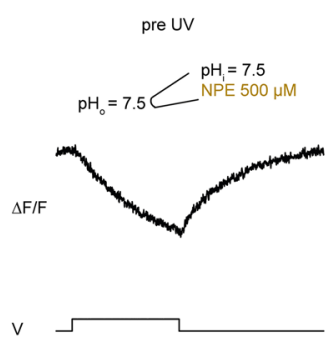

D

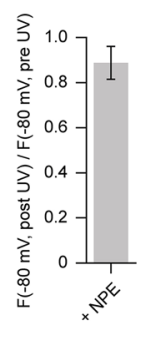

B

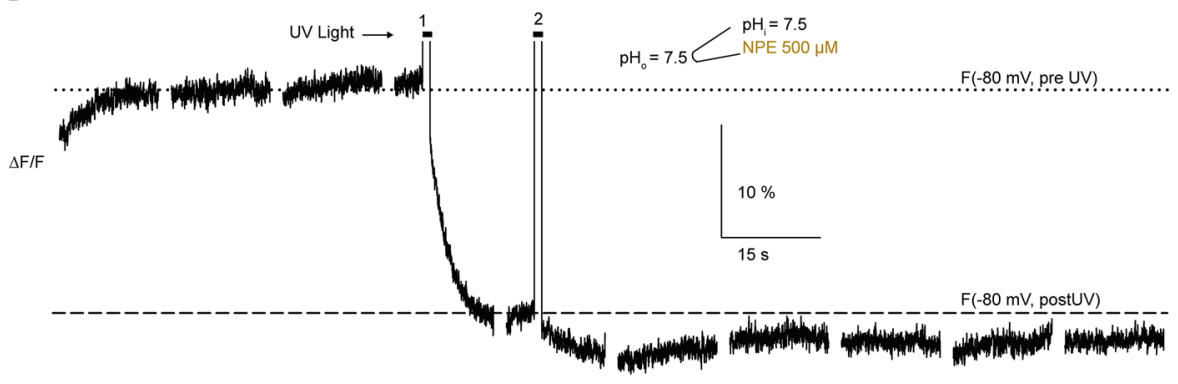

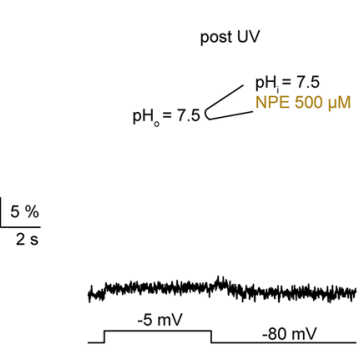

$\mathrm{E}$

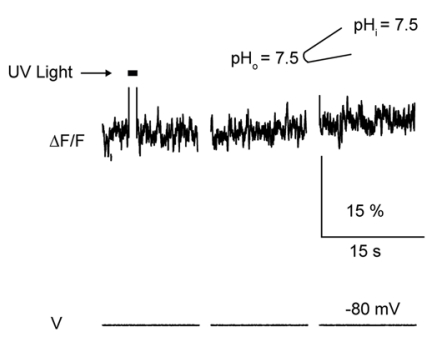
$-80 \mathrm{mV}$

Figure 5. Proton uncaging changes the $S 4$ conformation in closed state. (A) left, cartoon depicting ciHv1245C-TAMRA and chemical structure of NPE-caged-proton at the intracellular side. Right, scheme of the outside-out PCF recording condition with NPE-caged-proton in the pipette. (B) representative outside-out PCF recording of ciHv1-L245C-TAMRA held at $-80 \mathrm{mV}$, and $1 \mathrm{~s}$ UV-light exposure at time points indicated by bars. Horizontal lines (dotted = pre UV, dashed = after UV) indicate the fluorescence at $-80 \mathrm{mV}$. (C) mean $\mathrm{F}_{\text {signals }}$ in response to repetitive voltage steps from $-80 \mathrm{mV}$ to $-5 \mathrm{mV}$ before $\mathrm{UV}$ (left) and after UV (right). (D) fluorescence ratio, after and before $1 \mathrm{~s}$ UV-light exposure, at $-80 \mathrm{mV}(0.9 \pm 0.07 ; \mathrm{n}=3$ different patches from 3 different cells). (E) representative outside-out PCF recording of ciHv1-L245C-TAMRA without NPE in the pipette, held at $-80 \mathrm{mV}$, and $1 \mathrm{~s} \mathrm{UV-light} \mathrm{exposure} \mathrm{at} \mathrm{time} \mathrm{point} \mathrm{indicated} \mathrm{by} \mathrm{bar.} \mathrm{Error} \mathrm{bars} \mathrm{indicate} \mathrm{the} \mathrm{SD.}$

by uncaging NPE-caged-proton at the intracellular side in excised outside-out patches containing ciHv1. Prior to UV light, no or minimal outward proton currents were recorded in response to voltage steps from -50 to + $5 \mathrm{mV}$ (Fig. 4F). During depolarization, a 1-s-long UV-light stimulus increased the proton-current amplitude significantly $\left(\mathrm{I}_{\text {pre }}=0.96 \pm 0.9 \mathrm{pA}\right.$, vs. $\mathrm{I}_{\text {post }}=5.5 \pm 4.1 \mathrm{pA}$; student's paired t-test, $\left.p=0.01 ; \mathrm{n}=6\right)($ Fig. $4 \mathrm{~F})$, suggesting that uncaging of NPE-caged-proton acidified the intracellular side of the membrane and increased the chemical driving force for protons and increased the opening probability of Hv1. Taken together, UV-light induced uncaging of NPE-caged-proton can rapidly and transiently acidify the pipette solution at the excised membrane patch.

Motion of the S4 segment can be induced by proton uncaging. Next, we tested whether changing $\mathrm{pH}$ by proton uncaging can also induce conformational changes of the S4 voltage sensor. NPE-caged-proton was uncaged at the intracellular side of an outside-out patch containing ciHv1-L245C-TAMRA while at the same time changes of the fluorescence were recorded with PCF (Fig. 5A). The membrane patch was clamped at $80 \mathrm{mV}$ throughout the experiment, keeping ciHv1-L245C-TAMRA in a non-conducting, closed state (Fig. 5B). During the 1-s long UV-light stimulus, which bled through to the camera, the fluorescence recording could not be interpreted. After the UV-light stimulus, the fluorescence decreased monotonically to a lower steady-state fluorescence intensity (Fig. 5B,D). In contrast, a UV-light stimulus did not change the fluorescence when the patch pipette did not contain caged protons (Fig. 5E), suggesting that it is not the UV-light stimulus directly but indeed the proton uncaging that is responsible for the change in fluorescence. The mean steady-state fluorescence ratio between before and after the light stimulus at $-80 \mathrm{mV}(\mathrm{F}(-80 \mathrm{mV}$, post $\mathrm{UV}) / \mathrm{F}(-80 \mathrm{mV}$, pre UV)) decreased (Fig. 5D), which is in agreement with the change in the fluorescence ratio in response to intracellular acidification $(\Delta \mathrm{pH}>0)$ by gravity-driven perfusion (Fig. 3C, right). Therefore, acidification by proton uncaging corroborates our results from acidification by gravity-driven perfusion, suggesting that the decrease in fluorescence reports on movement of $\mathrm{S} 4$ in response to $\Delta \mathrm{pH}$. To test whether $\mathrm{F}_{\text {signal }}$ is also changed by proton uncaging, proton currents were elicited by depolarizing voltage steps during PCF recordings. The mean $\mathrm{F}_{\text {signal }}$ (same patch as in Fig. 5B) is shown in Fig. 5C. When $\mathrm{pH}_{\mathrm{i}}$ was lowered by proton uncaging, $\mathrm{F}_{\text {signal }}$ was altered similarly as seen with gravity-driven perfusion of a solution with a lower $\mathrm{pH}_{\mathrm{i}}$ : The voltage step to $-5 \mathrm{mV}$ induced an increase rather than a decrease of the fluorescence as compared to the $\Delta \mathrm{pH}=0$ condition; upon stepping back to $-80 \mathrm{mV}$, the fluorescence returned to baseline fluorescence intensity (compare Fig. $5 \mathrm{C}$ with Fig. 3B). Taken together, both methods proton uncaging and gravity-driven perfusion, show that the $\mathrm{S} 4$ segment changes its conformation when a $\Delta \mathrm{pH}$ is applied (by lowering $\mathrm{pH}_{\mathrm{i}}$ ). 
A

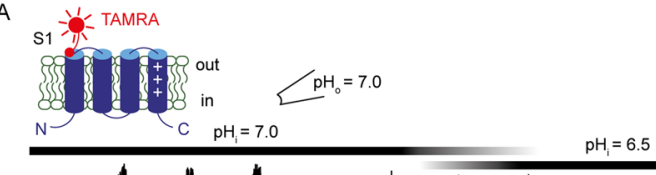

$\mathrm{pH}_{1}=7.0$

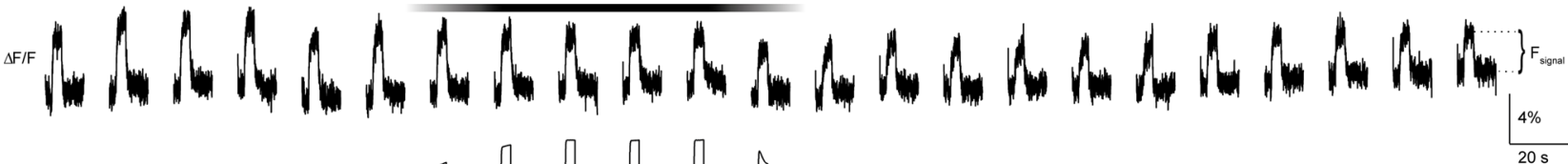
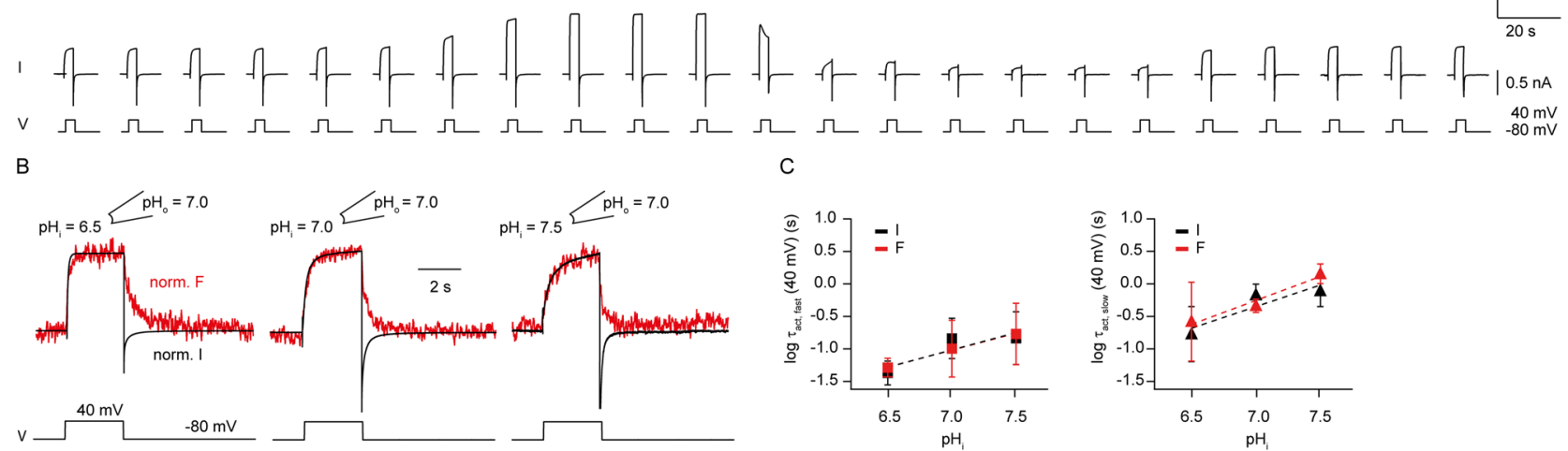

D

$E$
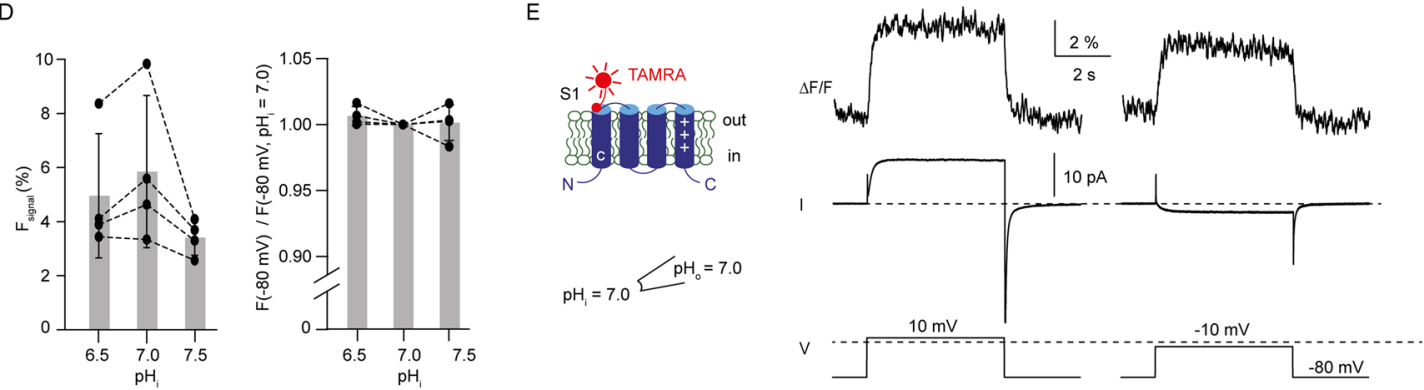

Figure 6. Changes in $\mathrm{pH}_{\mathrm{i}}$ do not uncouple gating from $\mathrm{S} 1$ motion. (A) representative inside-out PCF recording of ciHv1-I175C-TAMRA in response to repetitive voltage steps from $-80 \mathrm{mV}$ to $+40 \mathrm{mV}$ and back while changing $\mathrm{pH}_{\mathrm{i}}$ and keeping $\mathrm{pH}_{\mathrm{o}}=7.0$. (B) overlay of normalized mean current and fluorescence derived from the recording in (A). (C) mean fast (left) and slow (right) activation time constants of current (black) and $\mathrm{F}_{\text {signal }}$ (red) of ciHv1-I175C-TAMRA as function of $\mathrm{pH}_{\mathrm{i}}$ while $\mathrm{pH}_{\mathrm{o}}=7$ (see also Table 4). The dashed lines are linear fits with the following slopes: $\operatorname{slope}\left(\tau_{\text {I fast }}\right)=-0.5 \log (\mathrm{s}) / \Delta \mathrm{pH}$ unit, $\mathrm{r}^{2}=0.3$, n.s.; $\operatorname{slope}\left(\tau_{\mathrm{F} \text { fast }}\right)=-0.5 \log (\mathrm{s}) / \Delta \mathrm{pH}$ unit, $\mathrm{r}^{2}=0.4, p<0.05 ; \operatorname{slope}\left(\tau_{\text {I slow }}\right)=-0.67 \log (\mathrm{s}) / \Delta \mathrm{pH}$ unit, $\mathrm{r}^{2}=0.5, p<0.05 ; \operatorname{slope}\left(\tau_{\mathrm{F} \text { slow }}\right)=-0.73 \log (\mathrm{s}) / \Delta \mathrm{pH}$ unit, $\mathrm{r}^{2}=0.5, p<0.05$; $\operatorname{slope}\left(\tau_{\text {I fast }}\right)$ vs. $\operatorname{slope}\left(\tau_{\mathrm{F} \text { fast }}\right)$, n.s.; slope $\left(\tau_{\text {I slow }}\right)$ vs. slope $\left(\tau_{\mathrm{F} \mathrm{slow}}\right)$, n.s. $(\mathbf{D})$ left, amplitude of $\mathrm{F}_{\text {signal }}$ as a function of $\mathrm{pH}_{\mathrm{i}}$ while $\mathrm{pH}_{\mathrm{o}}=7.0\left(\mathrm{n}=4\right.$ patches from 4 different cells). For $\mathrm{pH}_{\mathrm{i}}=6.5, \mathrm{~F}_{\text {signal }}=5.0 \pm 2.3$; for $\mathrm{pH}_{\mathrm{i}}=7.0, \mathrm{~F}_{\text {signal }}=5.8 \pm 2.8$; for $\mathrm{pH}_{\mathrm{i}}=7.5, \mathrm{~F}_{\text {signal }}=3.4 \pm 0.6$; one-way ANOVA, $p=0.3$. Right, baseline fluorescence at $-80 \mathrm{mV}(\mathrm{F}(-80 \mathrm{mV}))$ for different $\mathrm{pH}_{\mathrm{i}}$ while $\mathrm{pH}_{\mathrm{o}}=7.0$, normalized to $\mathrm{F}(-80 \mathrm{mV})$ for $\mathrm{pH}_{\mathrm{i}}=7.0(\mathrm{n}=4$ patches from 4 different cells). For $\mathrm{pH}_{\mathrm{i}}=6.5, \mathrm{~F}(-80 \mathrm{mV})=1.006 \pm 0.007$; for $\mathrm{pH}_{\mathrm{i}}=7.5, \mathrm{~F}(-80 \mathrm{mV})=1.001 \pm 0.013$; oneway ANOVA, $p=0.5$. (E) representative inside-out PCF recording of ciHv1-I153C-I175C-TAMRA in response to voltage steps from -80 to +10 (left) or $-10 \mathrm{mV}$ (right). Dashed line at the bottom indicates $0 \mathrm{mV}$. Error bars indicate SD.

S1 gating motion is not uncoupled from channel opening by changes in $\mathrm{pH}_{\mathrm{i}}$. During pore opening, Hv1 undergoes another conformational change that can be monitored fluorometrically at the extracellular end of $\mathrm{S} 1$ (position $\mathrm{I} 175 \mathrm{C}$ in ciHv1) ${ }^{22}$. To test whether a change in $\Delta \mathrm{pH}$ also directly affects $\mathrm{S} 1$ motion, we used mutant ciHv1-I175C to label S1 with TAMRA and performed PCF recordings (Fig. 6A). During recording from an excised inside-out patch containing ciHv1-I175C-TAMRA, we changed $\Delta \mathrm{pH}$ by switching to solutions of different $\mathrm{pH}_{\mathrm{i}}$, while $\mathrm{pH}_{\mathrm{o}}$ was kept constant (7.0) and repetitively stepped from $-80 \mathrm{mV}$ to $+40 \mathrm{mV}$ and back (Fig. 6A). To better compare outward currents and fluorescence signals, normalized averages of the data from Fig. $6 \mathrm{~A}$ are shown in Fig. 6B. As reported previously ${ }^{22}$, in response to a voltage step from $-80 \mathrm{mV}$ to $+40 \mathrm{mV}$, the $\mathrm{S} 1 \mathrm{~F}_{\text {signal }}$ and the outward current both increase with similar activation kinetics (Fig. 6A-C, Table 4). In contrast to the S4 $\mathrm{F}_{\text {signal }}$, the $\mathrm{S} 1 \mathrm{~F}_{\text {signal }}$ does not change drastically when $\Delta \mathrm{pH}$ is changed: the baseline fluorescence at $80 \mathrm{mV}$ did not change and the sign of the $\mathrm{S}_{1} \mathrm{~F}_{\text {signal }}$ remained positive (Fig. 6D). To show that the direction of current does not determine the sign and kinetics of the fluorescence change, we recorded from the double mutant ciHv1-I153C-I175C-TAMRA (Fig. 6E): as shown previously ${ }^{22}$, the I153C mutation shifts the GV relationship to more negative potentials as compared to wild type, so that inward currents can be recorded at negative membrane potentials. The same is true for ciHv1-I153C-I175C-TAMRA, allowing us to record inward currents at$10 \mathrm{mV}$ and outward currents at $+10 \mathrm{mV}$. For both conditions, the $\mathrm{S} 1 \mathrm{~F}_{\text {signal }}$ recorded at position I175C is positive 


\begin{tabular}{|l|l|l|l|l|l|}
\hline $\mathbf{p H}_{\mathbf{i}} / \mathbf{p H}_{\mathbf{o}}$ & $\boldsymbol{\tau}_{\text {I fast }}(\mathbf{s})$ & $\boldsymbol{\tau}_{\text {F fast }}(\mathbf{s})$ & $\boldsymbol{\tau}_{\text {I slow }}(\mathbf{s})$ & $\boldsymbol{\tau}_{\text {F slow }}(\mathbf{s})$ & $\mathbf{n}$ \\
\hline $6.5 / 7.0$ & $0.05 \pm 0.02$ & $0.05 \pm 0.01$ & $0.23 \pm 0.14$ & $0.44 \pm 0.21$ & 4 \\
\hline $7.0 / 7.0$ & $0.17 \pm 0.12$ & $0.15 \pm 0.15$ & $0.7 \pm 0.3$ & $0.47 \pm 0.13$ & 4 \\
\hline $7.5 / 7.0$ & $0.2 \pm 0.1$ & $0.23 \pm 0.16$ & $0.9 \pm 0.5$ & $1.5 \pm 0.5$ & 4 \\
\hline
\end{tabular}

Table 4. Activation kinetics of the current and $\mathrm{F}_{\text {signal }}$ of ciHv1-I175C-TAMRA recorded at $\mathrm{pH}_{\mathrm{o}}=7.0$ (mean \pm SD).

and does not change the sign, confirming that the direction of current does not change the sign of S1 $\mathrm{F}_{\text {signal. }}$ The kinetics of the $\mathrm{S}_{1} \mathrm{~F}_{\text {signal }}$ and the outward current co-varied for different $\Delta \mathrm{pH}$ : intracellular acidification accelerated and alkalization decelerated kinetics of both the $\mathrm{S}_{1} \mathrm{~F}_{\text {signal }}$ and the outward current (Fig. 6C). Thus, current and $\mathrm{S} 1 \mathrm{~F}_{\text {signal }}$ kinetics stay coupled even when $\Delta \mathrm{pH}$ is changed, corroborating that $\Delta \mathrm{pH}$ - and voltage-sensing are linked to each other via the $\mathrm{S} 4$ voltage sensor.

\section{Discussion}

Several ion channels are gated or allosterically modulated by $\mathrm{pH}^{40}$. For some channels (e.g. two P-domain $\mathrm{K}^{+}$ channels), the amino-acid residues that convey $\mathrm{pH}$ sensitivity, presumably by titration of acidic or basic side chains, are well characterized ${ }^{41,42}$. However, Hv1 is modulated by $\Delta \mathrm{pH}$ rather than $\mathrm{pH}_{\mathrm{i}}$ or $\mathrm{pH}_{\mathrm{o}}$ itself. Although some mutations have been reported to affect $\Delta \mathrm{pH}$ sensing of $\mathrm{Hv}^{26,28,30}$, a clear identification of amino-acid residues that constitute the $\Delta \mathrm{pH}$ sensor(s) is lacking. Here, we provide direct evidence that the S4 segment alters its conformation in response to changes in $\Delta \mathrm{pH}$, suggesting that $\mathrm{S} 4$ serves as both voltage- and $\Delta \mathrm{pH}$-sensor.

During voltage-dependent gating, Hv1 proceeds through multiple transitions ${ }^{36,37,43-45}$. VCF recordings show that membrane depolarization moves the S4 voltage sensor to an activated state, followed by a second transition that leads to the open state ${ }^{36}$. Taking advantage of precise intra- and extracellular $\mathrm{pH}$ control in the PCF configuration, we show that the transitions monitored at $\mathrm{S} 4$ are, except for the activation kinetics, relatively similar for different symmetric $\mathrm{pH}$ conditions (Fig. $2 \mathrm{G}, \Delta \mathrm{pH}=0$ ), suggesting that the voltage dependence of voltage-sensor motion, like voltage-dependent gating, does not depend on $\mathrm{pH}$ itself. By contrast, asymmetric $\mathrm{pH}$ conditions can lead to a drastic change of the $\mathrm{F}_{\text {ignal }}$ on $\mathrm{S} 4$ (Figs. 3 and 5), suggesting that voltage and $\Delta \mathrm{pH}$ are the key stimuli to drive $\mathrm{S} 4$ conformational changes.

Recently, two studies investigated Hv1 mutants with diminished ionic currents and could identify gating currents, which reflect the movement of charged amino-acids side chains across the electric field of the membrane ${ }^{44,45}$. Interestingly, gating currents of human Hv1-W207A-N214R were shown to be sensitive to $\mathrm{pH}_{\mathrm{o}}$ : extracellular acidification by one $\mathrm{pH}$ unit shifts the gating charge-voltage relationship towards positive membrane potentials by $40 \mathrm{mV}^{45}$. Because $\mathrm{S} 4$ contains the majority of gating charges ${ }^{43}$, the $\mathrm{pH}_{\mathrm{o}}$ sensitivity of gating currents suggests that the $\mathrm{S} 4$ conformation depends on $\mathrm{pH}_{\mathrm{o}}$. Our results show that the $\mathrm{S} 4$ conformation is also sensitive to $\mathrm{pH}_{\mathrm{i}}$. This is in agreement with a previous study that suggested that the gating transitions for Hvl activation depend on $\mathrm{pH}_{\mathrm{i}}^{37}$.

Taken together, these results are consistent with the idea that excessive protons at the intracellular side (low $\mathrm{pH}_{\mathrm{i}}$ ) or a positive membrane potential push $\mathrm{S} 4$ to the extracellular side; excessive protons at the extracellular side $\left(\right.$ low $\mathrm{pH}_{\mathrm{o}}$ ) or a negative membrane potential push $\mathrm{S} 4$ to the intracellular side (Fig. 7A). Therefore, we suggest that both $\Delta \mathrm{pH}$ and voltage determine the position of $\mathrm{S} 4$ in the membrane (Fig. 7B). Hv1 might enter states by changes in $\Delta \mathrm{pH}$ that are different from states by changes in membrane potential. Whether $\Delta \mathrm{pH}$ sensing is restricted to only certain conformational states, remains unclear and thus a subject for future studies. Our PCF experiments provide strong evidence that $\mathrm{S} 4$ conformation can be changed by $\mathrm{pH}_{\mathrm{i}}$ in the resting-state (Figs. 3, 5). Our proton uncaging experiments show that the open state is sensitive to changes in $\mathrm{pH}_{\mathrm{o}}$ (Fig. $4 \mathrm{~A}$ ). In a previous study of human Hv1, mutation of the first of the three arginines of the S4 segment to histidine ("R1H”) creates an additional, hyperpolarization-activated proton conductance, termed shuttle conductance ${ }^{46}$. The shuttle conductance was found to be $\mathrm{pH}_{\mathrm{o}}$-sensitive, which might reflect the $\Delta \mathrm{pH}$-sensitivity of the S4 segment for transitions between resting (non-open) states at negative membrane potentials.

Different molecular mechanism of $\Delta \mathrm{pH}$ sensing are currently under debate ${ }^{47}$. Protonation or deprotonation of amino-acid residues can induce conformational changes in proteins. In Hvl, there might be distinct, protonable amino-acid residues serving as $\mathrm{pH}$ sensors at either side of the membrane for detecting $\mathrm{pH}_{\mathrm{o}}$ and $\mathrm{pH}_{\mathrm{i}}$, respectively ${ }^{24}$. S4 contains only three arginines as potentially titratable amino-acid side chains, and those might be difficult to deprotonate under physiological conditions. If any of those arginines were deprotonated over the tested $\mathrm{pH}$ range, we would expect a significant change in voltage sensitivity, which should result in shallower slopes of the GVs. However, slopes for different $\mathrm{pH}$ conditions did not change significantly (Table 1). Alternatively, the negatively charged amino-acid residues in transmembrane segments S1-S3, which serve as countercharges of the arginine residues, might participate in $\mathrm{pH}$ sensing ${ }^{48}$; titration of those residues might weaken their interaction with the arginine residues and, therefore, influence the S4 conformation. However, because $\Delta \mathrm{pH}$ and not the $\mathrm{pH}$ itself determines gating, sensors for $\mathrm{pH}_{\mathrm{o}}$ and $\mathrm{pH}_{\mathrm{i}}$ need to be influenced by or functionally linked to each other. The strict dependence of $\mathrm{V}_{1 / 2}$ on $\Delta \mathrm{pH}$, which is remarkable linear over a large $\mathrm{pH}$ range ${ }^{26}$, argues against titratable amino-acid residues as $\mathrm{pH}$ sensors: the $\mathrm{pK}_{\mathrm{a}} \mathrm{s}$ of the intra- and extracellular sensor would need to be coupled in a symmetric fashion which appears implausible.

It has been suggested that water molecules could be an important component in mediating $\Delta \mathrm{pH}$ sensitivity. Molecular dynamics simulations suggest that the core of the VSD of Hvl contains more water molecules than 
A
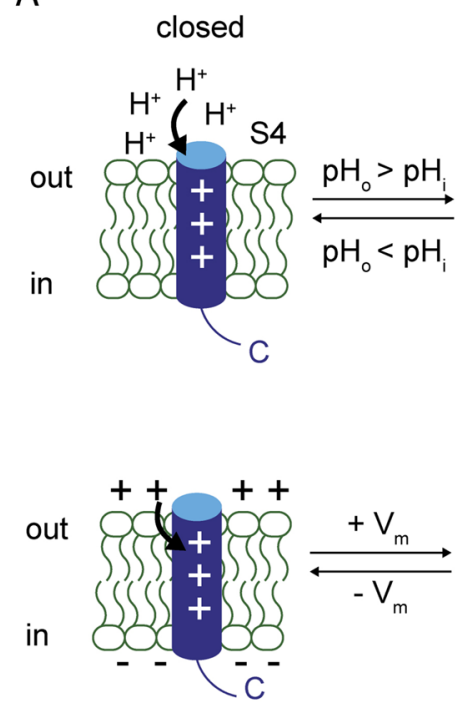

activated
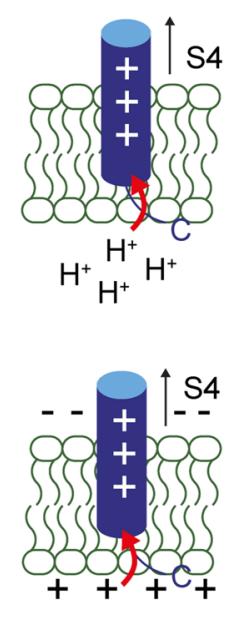

B

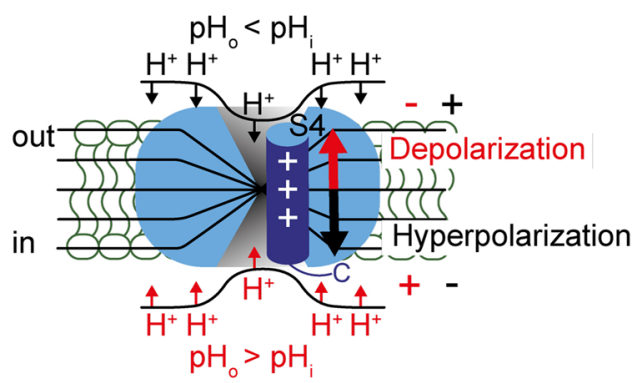

Figure 7. Both $\Delta \mathrm{pH}$ and the membrane potential control S4 conformation. (A) proposed S4 conformation in the membrane as a function of either $\Delta \mathrm{pH}$ (top) or voltage (bottom). Protons on one side of the membrane move S4 to the opposite side of the membrane (top), similar to the effect of membrane voltage (bottom). S1-S3 are omitted for clarity. "+" signs denote the charged arginines in S4. (B) cartoon depicting how S4 position is determined by both voltage and $\Delta \mathrm{pH}$ across the membrane. Protons might exert electrostatic forces on Hv1, i.e. by protonation of a water wire in the VSD. The position of the mobile S4 segment depends on both, the electrochemical potential for protons and the membrane potential: excessive protons at the extracellular side $\left(\mathrm{pH}_{\mathrm{o}}<\mathrm{pH}_{\mathrm{i}}\right)$ and/or hyperpolarization push $\mathrm{S} 4$ to the intracellular side, stabilizing the closed state. Excessive protons at the intracellular side $\left(\mathrm{pH}_{\mathrm{o}}>\mathrm{pH}_{\mathrm{i}}\right)$ and/or depolarization push $\mathrm{S} 4$ to the extracellular side, stabilizing the activated state.

the VSD of classical voltage-gated ion channels ${ }^{26}$. Indeed, several solvent accessible amino-acid residues are located deep inside the crevice of the $\mathrm{VSD}^{49}$. The water molecules might form a robust water wire network with limited mobility within the VSD. Protonation of this network could lead to a rearrangement of the hydrogen bonding and exert electrostatic forces that change S4 conformation ${ }^{26}$. Such a mechanism is not localizable to the Hv1 channel itself; it would be a distributed effect acting on the channel. A previous study on $\mathrm{Zn}^{2+}$ sensitivity in Hv1 provides evidence for allosteric coupling between intra- and extracellular residues induced through coulombic interactions ${ }^{50}$. This supports the idea that changes in electrostatic forces might be processed over a long distance across the membrane.

We did not find evidence for direct $\Delta \mathrm{pH}$-induced conformational changes of the S1 segment, reinforcing the idea that the mechanisms of $\Delta \mathrm{pH}$ - and voltage-sensing are intimately linked to each other via the S4 voltage sensor. However, we cannot rule out the possibility that the $\mathrm{S} 4$ segment is coupled to other -still unknown- $\Delta \mathrm{pH}$ sensing elements. Further studies are therefore needed to further characterize the $\Delta \mathrm{pH}$-induced conformational changes of the S4 segment as well as possible additional conformational changes involving other segments.

It is not known whether only the S4 segment of Hvl is $\Delta \mathrm{pH}$ sensitive, or whether the S4 segments of other voltage-gated ion channels are also $\Delta \mathrm{pH}$ sensitive. The $\Delta \mathrm{pH}$-induced $\mathrm{S} 4$ movement during non-conducting states suggests that actual proton permeation is not a prerequisite for $\Delta \mathrm{pH}$ sensing. Possibly, changes in $\Delta \mathrm{pH}$ can induce motions in the VSDs of other voltage-gated ion channels that do not necessarily couple to channel opening and therefore might have escaped from being noticed in electrophysiological recordings. The higher water densities in Hvl compared to other VSDs might play a key role for $\Delta \mathrm{pH}$ sensing by enabling an interaction of protons with S4.

Our data suggest that the functional coupling between $\mathrm{pH}_{\mathrm{o}}$ and $\mathrm{pH}_{\mathrm{i}}$ sensor(s) is provided by the mobile S4 voltage sensor, serving as a whole as the " $\Delta \mathrm{pH}$-sensing element". In this setting, the electrochemical potential for protons across the membrane, together with the membrane potential, determines the position of S4 in the membrane (Fig. 7B), and thereby sets the voltage of half-aximal channel activation. Of note, the $\Delta \mathrm{pH}$-induced shift of $\mathrm{V}_{1 / 2}$, reported to amount to $-0 \mathrm{mV} / \Delta \mathrm{pH}$ unit in the literature and to -47 to $-57 \mathrm{mV} / \Delta \mathrm{pH}$ unit for the channels investigated in our study, is close to the electrochemical potential for protons $(-59 \mathrm{mV} / \Delta \mathrm{pH}$ unit), suggesting an immediate link between gating and the permeant ion. Deviations might arise from differences between ion concentration and activity. Mutations that limit water exposure to S4 should decrease $\Delta \mathrm{pH}$ sensing; those mutations, however, are likely to limit conduction as well. Clearly, the identification of the detailed molecular mechanism behind $\Delta \mathrm{pH}$ sensing of Hvl requires further studies using electrophysiological, proton uncaging, and fluorometric techniques on mutants of Hv1 as well as modeling approaches that take the potential profiles around Hv1 into consideration. 


\section{Data availability}

The datasets generated during and/or analyzed during the current study are available from the corresponding author on reasonable request.

Received: 14 August 2020; Accepted: 28 October 2020

Published online: 04 December 2020

\section{References}

1. Ramsey, I. S., Moran, M. M., Chong, J. A. \& Clapham, D. E. A voltage-gated proton-selective channel lacking the pore domain. Nature 440, 1213-1216 (2006).

2. Sasaki, M., Takagi, M. \& Okamura, Y. A voltage sensor-domain protein is a voltage-gated proton channel. Science 312, 589-592 (2006).

3. Taylor, A. R., Chrachri, A., Wheeler, G., Goddard, H. \& Brownlee, C. A voltage-gated $\mathrm{H}^{+}$channel underlying pH homeostasis in calcifying coccolithophores. PLoS Biol. 9, 1-14 (2011).

4. Ramsey, I. S., Ruchti, E., Kaczmarek, J. S. \& Clapham, D. E. Hv1 proton channels are required for high-level NADPH oxidasedependent superoxide production during the phagocyte respiratory burst. Proc. Natl. Acad. Sci. USA 106, 7642-7647 (2009).

5. Capasso, M. et al. HVCN1 modulates BCR signal strength via regulation of BCR-dependent generation of reactive oxygen species. Nat. Immunol. 11, 265-272 (2010).

6. Iovannisci, D., Illek, B. \& Fischer, H. Function of the HVCN1 proton channel in airway epithelia and a naturally occurring mutation, M91T. J. Gen. Physiol. 136, 35-46 (2010).

7. Lishko, P. V., Botchkina, I. L., Fedorenko, A. \& Kirichok, Y. Acid extrusion from human spermatozoa is mediated by flagellar voltage-gated proton channel. Cell 140, 327-337 (2010).

8. Morgan, D. et al. Voltage-gated proton channels maintain $\mathrm{pH}$ in human neutrophils during phagocytosis. Proc. Natl. Acad. Sci. USA 106, 18022-18027 (2009).

9. El Chemaly, A. et al. VSOP/Hv1 proton channels sustain calcium entry, neutrophil migration, and superoxide production by limiting cell depolarization and acidification. J. Exp. Med. 207, 129-139 (2010).

10. Wu, L.-J. et al. The voltage-gated proton channel Hvl enhances brain damage from ischemic stroke. Nat. Neurosci. 15, 565-573 (2012).

11. Wang, Y., Li, S. J., Wu, X., Che, Y. \& Li, Q. Clinicopathological and biological significance of human voltage-gated proton channel Hv1 protein overexpression in breast cancer. J. Biol. Chem. 287, 13877-13888 (2012).

12. Hondares, E. et al. Enhanced activation of an amino-terminally truncated isoform of the voltage-gated proton channel HVCN1 enriched in malignant B cells. Proc. Natl. Acad. Sci. USA 111, 18078-18083 (2014).

13. Lee, S.-Y., Letts, J. A. \& MacKinnon, R. Functional reconstitution of purified human Hv1 H+ channels. J. Mol. Biol. 387, 1055-1060 (2009).

14. Koch, H. P. et al. Multimeric nature of voltage-gated proton channels. Proc. Natl. Acad. Sci. USA 105, 9111-9116 (2008).

15. Lee, S.-Y., Letts, J. A. \& MacKinnon, R. Dimeric subunit stoichiometry of the human voltage-dependent proton channel Hv1. Proc. Natl. Acad. Sci. USA 105, 7692-7695 (2008).

16. Tombola, F., Ulbrich, M. H. \& Isacoff, E. Y. The voltage-gated proton channel Hv1 has two pores, each controlled by one voltage sensor. Neuron 58, 546-556 (2008).

17. Fujiwara, Y., Kurokawa, T. \& Okamura, Y. Long a helices projecting from the membrane as the dimer interface in the voltage-gated $\mathrm{H}^{+}$channel. J. Gen. Physiol. 143, 377-386 (2014).

18. Gonzalez, C., Koch, H. P., Drum, B. M. \& Larsson, H. P. Strong cooperativity between subunits in voltage-gated proton channels. Nat. Struct. Mol. Biol. 17, 51-56 (2010).

19. Tombola, F., Ulbrich, M. H., Kohout, S. C. \& Isacoff, E. Y. The opening of the two pores of the Hv1 voltage-gated proton channel is tuned by cooperativity. Nat. Struct. Mol. Biol. 17, 44-50 (2010).

20. Berger, T. K. \& Isacoff, E. Y. The pore of the voltage-gated proton channel. Neuron 72, 991-1000 (2011).

21. Musset, B. et al. Aspartate 112 is the selectivity filter of the human voltage-gated proton channel. Nature 7376, 273-277 (2011).

22. Mony, L., Berger, T. K. \& Isacoff, E. Y. A specialized molecular motion opens the Hv1 voltage-gated proton channel. Nat. Struct. Mol. Biol. 22, 283-290 (2015).

23. Musset, B. et al. Detailed comparison of expressed and native voltage-gated proton channel currents. J. Physiol. 586, 2477-2486 (2008).

24. Cherny, V. V., Markin, V. S. \& DeCoursey, T. E. The voltage-activated hydrogen ion conductance in rat alveolar epithelial cells is determined by the $\mathrm{pH}$ gradient. J. Gen. Physiol. 105, 861-896 (1995).

25. Smith, S. M. E. et al. Voltage-gated proton channel in a dinoflagellate. Proc. Natl. Acad. Sci. USA 108, 18162-18167 (2011).

26. Ramsey, I. S. et al. An aqueous $\mathrm{H}^{+}$permeation pathway in the voltage-gated proton channel Hv1. Nat. Struct. Mol. Biol. 17, 869-875 (2010).

27. Cherny, V. V. et al. Tryptophan 207 is crucial to the unique properties of the human voltage-gated proton channel, hH $H_{v}$. J. Gen. Physiol. 146, 343-356 (2015).

28. Cherny, V. V., Morgan, D., Thomas, S., Smith, S. M. E. \& DeCoursey, T. E. Histidine ${ }^{168}$ is crucial for $\Delta \mathrm{pH}$-dependent gating of the human voltage-gated proton channel, $\mathrm{hH}_{\mathrm{v}} \mathrm{l}$. J. Gen. Physiol. 150, 851-862 (2018).

29. De la Rosa, V., Suárez-Delgado, E., Rangel-Yescas, G. E. \& Islas, L. D. Currents through Hv1 channels deplete protons in their vicinity. J. Gen. Physiol. 147, 127-136 (2016).

30. Berger, T. K. et al. Post-translational cleavage of $\mathrm{Hv1}$ in human sperm tunes $\mathrm{pH}$ - and voltage-dependent gating. J. Physiol. 595, 1533-1546 (2017)

31. Zheng, J. \& Zagotta, W. N. Patch-clamp fluorometry recording of conformational rearrangements of ion channels. Science's STKE 2003, PL7 (2003).

32. Berger, T. K. \& Isacoff, E. Y. Fluorescent labeling for patch-clamp fluorometry (PCF) measurements of real-time protein motion in ion channels. Meth. Mol. Biol. 1266, 93-106 (2015).

33. Mannuzzu, L. M., Moronne, M. M. \& Isacoff, E. Y. Direct physical measure of conformational rearrangement underlying potassium channel gating. Science 271, 213-216 (1996).

34. Cha, A. \& Bezanilla, F. Characterizing voltage-dependent conformational changes in the Shaker $\mathrm{K}^{+}$channel with fluorescence. Neuron 19, 1127-1140 (1997).

35. Takeshita, K. et al. X-ray crystal structure of voltage-gated proton channel. Nat. Struct. Mol. Biol. 21, 352-357 (2014).

36. Qiu, F., Rebolledo, S., Gonzalez, C. \& Larsson, H. P. Subunit interactions during cooperative opening of voltage-gated proton channels. Neuron 77, 288-298 (2013).

37. Villalba-Galea, C. A. Hvl proton channel opening is preceded by a voltage-independent transition. Biophys. J. 107, 1564-1572 (2014).

38. Lapointe, J. Y. \& Szabo, G. A novel holder allowing internal perfusion of patch-clamp pipettes. Pflug. Arch. Eur. J. Phys. 410, 212-216 (1987). 
39. Barth, A. \& Corrie, J. E. T. Characterization of a new caged proton capable of inducing large pH jumps. Biophys. J. 83, 2864-2871 (2002).

40. Zheng, J. \& Trudeau, C. M. (eds) Handbook of Ion Channels (CRC Press, Boca Raton, 2015).

41. Maingret, F., Patel, A. J., Lesage, F., Lazdunski, M. \& Honoré, E. Mechano- or acid stimulation, two interactive modes of activation of the TREK-1 potassium channel. J. Biol. Chem. 274, 26691-26696 (1999).

42. Sandoz, G., Douguet, D., Chatelain, F., Lazdunski, M. \& Lesage, F. Extracellular acidification exerts opposite actions on TREK1 and TREK2 potassium channels via a single conserved histidine residue. Proc. Natl. Acad. Sci. USA 106, 14628-14633 (2009).

43. Gonzalez, C., Rebolledo, S., Perez, M. E. \& Larsson, H. P. Molecular mechanism of voltage sensing in voltage-gated proton channels. J. Gen. Physiol. 141, 275-285 (2013).

44. Carmona, E. M. et al. Gating charge displacement in a monomeric voltage-gated proton Hv1 channel. Proc. Natl. Acad. Sci. USA 115, 9240-9245 (2018).

45. De La Rosa, V. \& Ramsey, I. S. Gating Currents in the Hv1 Proton Channel. Biophys. J. 114, 2844-2854 (2018).

46. Randolph, A. L., Mokrab, Y., Bennett, A. L., Sansom, M. S. \& Ramsey, I. S. Proton currents constrain structural models of voltage sensor activation. eLife 5, 1-29 (2016).

47. Islas, L. D. The acid test for pH-dependent gating in cloned Hvl channels. J. Gen. Physiol. 150, 781-782 (2018).

48. DeCoursey, T. E. Voltage and pH sensing by the voltage-gated proton channel, Hv1. J. R. Soc. Interface 15 (2018).

49. Kurokawa, T. \& Okamura, Y. Mapping of sites facing aqueous environment of voltage-gated proton channel at resting state: a study with PEGylation protection. Biochim. Biophys. Acta 1838, 382-387 (2014).

50. De La Rosa, V., Bennett, A. L. \& Ramsey, I. S. Coupling between an electrostatic network and the Zn2+-binding site modulates Hv1 activation. J. Gen. Physiol. 150, 863-881 (2018).

\section{Acknowledgements}

We thank U. B. Kaupp for insightful discussions, S. Wolf-Kümmeth for technical assistance, Y. Okamura (Osaka University) for the cDNA of Ciona intestinalis Hv1, and C. Volk for the generous donation of frog oocytes.

\section{Author contributions}

T.K.B. conceived and designed the study. T.M.S. acquired and analyzed the data. Both authors interpreted data and wrote and revised the manuscript.

\section{Funding \\ Open Access funding enabled and organized by Projekt DEAL.}

\section{Competing interests}

The authors declare no competing interests.

\section{Additional information}

Correspondence and requests for materials should be addressed to T.K.B.

Reprints and permissions information is available at www.nature.com/reprints.

Publisher's note Springer Nature remains neutral with regard to jurisdictional claims in published maps and institutional affiliations.

(c) Open Access This article is licensed under a Creative Commons Attribution 4.0 International (c) License, which permits use, sharing, adaptation, distribution and reproduction in any medium or format, as long as you give appropriate credit to the original author(s) and the source, provide a link to the Creative Commons licence, and indicate if changes were made. The images or other third party material in this article are included in the article's Creative Commons licence, unless indicated otherwise in a credit line to the material. If material is not included in the article's Creative Commons licence and your intended use is not permitted by statutory regulation or exceeds the permitted use, you will need to obtain permission directly from the copyright holder. To view a copy of this licence, visit http://creativecommons.org/licenses/by/4.0/.

(C) The Author(s) 2020 